\title{
Curcumin Pretreatment Prevents Potassium Dichromate-Induced Hepatotoxicity, Oxidative Stress, Decreased Respiratory Complex I Activity, and Membrane Permeability Transition Pore Opening
}

\author{
Wylly Ramsés García-Niño, ${ }^{1}$ Edilia Tapia, ${ }^{2}$ Cecilia Zazueta, ${ }^{3}$ \\ Zyanya Lucía Zatarain-Barrón, ${ }^{4}$ Rogelio Hernández-Pando, ${ }^{4}$ \\ Claudia Cecilia Vega-García, ${ }^{5}$ and José Pedraza-Chaverrí ${ }^{1}$ \\ ${ }^{1}$ Department of Biology, Faculty of Chemistry, National Autonomous University of Mexico (UNAM), University City, \\ 04510 Mexico City, DF, Mexico \\ ${ }^{2}$ Renal Pathophysiology Laboratory, Department of Nephrology, National Institute of Cardiology "Ignacio Chávez", \\ 14080 Mexico City, DF, Mexico \\ ${ }^{3}$ Department of Cardiovascular Biomedicine, National Institute of Cardiology "Ignacio Chávez", 14080 Mexico City, DF, Mexico \\ ${ }^{4}$ Experimental Pathology Section, National Institute of Medical Sciences and Nutrition "Salvador Zubirán", \\ 14000 Mexico City, DF, Mexico \\ ${ }^{5}$ Department of Preclinical Toxicology, National Polytechnic Institute, 14740 Mexico City, DF, Mexico
}

Correspondence should be addressed to Edilia Tapia; ediliatapia@hotmail.com and José Pedraza-Chaverrí; pedraza@unam.mx

Received 18 March 2013; Revised 7 June 2013; Accepted 16 June 2013

Academic Editor: Shrikant Anant

Copyright (C) 2013 Wylly Ramsés García-Niño et al. This is an open access article distributed under the Creative Commons Attribution License, which permits unrestricted use, distribution, and reproduction in any medium, provided the original work is properly cited.

\begin{abstract}
Curcumin is a polyphenol derived from turmeric with recognized antioxidant properties. Hexavalent chromium is an environmental toxic and carcinogen compound that induces oxidative stress. The objective of this study was to evaluate the potential protective effect of curcumin on the hepatic damage generated by potassium dichromate $\left(\mathrm{K}_{2} \mathrm{Cr}_{2} \mathrm{O}_{7}\right)$ in rats. Animals were pretreated daily by 9-10 days with curcumin $\left(400 \mathrm{mg} / \mathrm{kg}\right.$ b.w.) before the injection of a single intraperitoneal of $\mathrm{K}_{2} \mathrm{Cr}_{2} \mathrm{O}_{7}(15 \mathrm{mg} / \mathrm{kg}$ b.w.). Groups of animals were sacrificed 24 and $48 \mathrm{~h}$ later. $\mathrm{K}_{2} \mathrm{Cr}_{2} \mathrm{O}_{7}$-induced damage to the liver was evident by histological alterations and increase in the liver weight and in the activity of alanine aminotransferase, aspartate aminotransferase, lactate dehydrogenase, and alkaline phosphatase in plasma. In addition, $\mathrm{K}_{2} \mathrm{Cr}_{2} \mathrm{O}_{7}$ induced oxidative damage in liver and isolated mitochondria, which was evident by the increase in the content of malondialdehyde and protein carbonyl and decrease in the glutathione content and in the activity of several antioxidant enzymes. Moreover, $\mathrm{K}_{2} \mathrm{Cr}_{2} \mathrm{O}_{7}$ induced decrease in mitochondrial oxygen consumption, in the activity of respiratory complex I, and permeability transition pore opening. All the above-mentioned alterations were prevented by curcumin pretreatment. The beneficial effects of curcumin against $\mathrm{K}_{2} \mathrm{Cr}_{2} \mathrm{O}_{7}$-induced liver oxidative damage were associated with prevention of mitochondrial dysfunction.
\end{abstract}

\section{Introduction}

Curcumin or diferuloylmethane (1,7-bis[4-hydroxy-3-methoxyphenyl]-1,6-heptadiene-3,5-dione) is a hydrophobic polyphenol derived from turmeric: the rhizome of the herb Curcuma longa [1]. Traditionally, turmeric has been used in therapeutic preparations for various ailments in different parts of the world [2]. At present, turmeric is used as a dietary spice, by the food industry as additive, flavouring, preservative and as colouring agent in foods and textiles $[3,4]$. Curcumin is a major component of turmeric and it has been shown to exhibit antioxidant [5], antimicrobial [6], antiinflammatory [7], and anticarcinogenic [8] activities. 
The antihepatotoxic effects of curcumin against chemically induced hepatic damage are well documented, and they have been attributed to its intrinsic antioxidant properties [9]. Thus, curcumin has shown to protect liver against hepatic injury and fibrogenesis by suppressing hepatic inflammation [10], attenuating hepatic oxidative stress [11, 12], increasing expression of the xenobiotic detoxifying enzymes such as superoxide dismutase (SOD), catalase (CAT), glutathione peroxidase (GPx), glutathione- $S$-transferase (GST), glutathione reductase (GR), and $\mathrm{NAD}(\mathrm{P}) \mathrm{H}$ :quinone oxidoreductase $[5,13,14]$, inhibiting hepatic stellate cells activation [15-17], and supporting the mitochondrial function [18].

On the other hand, chromium exists in several oxidation states, being hexavalent chromium $[\mathrm{Cr}(\mathrm{VI})]$ and trivalent chromium [Cr(III)] the most stable forms. $\mathrm{Cr}(\mathrm{III})$ is predominantly present in the environment and in salts used as micronutrients and dietary supplements [19]. $\mathrm{Cr}(\mathrm{VI})$ salts such as potassium dichromate $\left(\mathrm{K}_{2} \mathrm{Cr}_{2} \mathrm{O}_{7}\right)$ or chromic acid are widely used in leather, chrome-plating, and dye-producing industries $[20,21]$. Occupational and environmental exposure to $\mathrm{Cr}(\mathrm{VI})$-containing compounds is known to be toxic, mutagenic, and carcinogenic to human beings and diverse animals [22-24], leading to serious damage to the kidneys $[25,26]$, liver $[27,28]$, lungs $[29,30]$, skin $[31]$, and other vital organs [32-34].

$\mathrm{Cr}(\mathrm{VI})$ is generally considered to be the toxic form, which can efficiently penetrate anionic channels in cellular membranes [35]. Inside cells, $\mathrm{Cr}(\mathrm{VI})$ is reduced through reactive intermediates $\mathrm{Cr}(\mathrm{V}), \mathrm{Cr}(\mathrm{IV})$, and to the more stable $\mathrm{Cr}(\mathrm{III})$ by cellular reductants such as glutathione, cysteine, ascorbic acid, and riboflavin and NADPH-dependent flavoenzymes [36]. In fact, the redox couples $\mathrm{Cr}(\mathrm{VI}) /(\mathrm{V}), \mathrm{Cr}(\mathrm{V}) /(\mathrm{IV})$, and $\mathrm{Cr}(\mathrm{III}) /(\mathrm{II})$ have been shown to serve as cyclical electron donors in a Fenton-like reaction, which generates reactive oxygen species (ROS) leading to genomic DNA damage and oxidative deterioration of lipids and proteins [37].

Liver is an organ capable of being injured by $\mathrm{Cr}(\mathrm{VI})$, and it has been demonstrated that the exposition to $\mathrm{K}_{2} \mathrm{Cr}_{2} \mathrm{O}_{7}$ induces hepatotoxicity associated to increased ROS levels [38], lipid peroxidation [39, 40], inhibition of antioxidant enzymes [41, 42], structural tissue injury [43, 44], and mitochondrial damage [45] including impaired mitochondrial bioenergetics [46, 47]. Natural and synthetic antioxidants have been reported to ameliorate or prevent $\mathrm{K}_{2} \mathrm{Cr}_{2} \mathrm{O}_{7}$ induced hepatotoxicity $[42,48,49]$. In this context, MolinaJijón et al. [50] have recently shown that curcumin pretreatment has a protective role in $\mathrm{K}_{2} \mathrm{Cr}_{2} \mathrm{O}_{7}$-induced nephrotoxicity, and Chandra et al. [51] demonstrated protective effects of curcumin against $\mathrm{K}_{2} \mathrm{Cr}_{2} \mathrm{O}_{7}$ in male reproductive system. However, to our knowledge, the potential antihepatotoxic protective effect of curcumin on $\mathrm{K}_{2} \mathrm{Cr}_{2} \mathrm{O}_{7}$ induced hepatotoxicity has not been explored. The purpose of this study was to explore the potential protective effect of curcumin pretreatment against the $\mathrm{K}_{2} \mathrm{Cr}_{2} \mathrm{O}_{7}$-induced hepatotoxicity, oxidative stress, and mitochondrial dysfunction.

\section{Materials and Methods}

2.1. Reagents and Antibodies. Curcumin, $\mathrm{K}_{2} \mathrm{Cr}_{2} \mathrm{O}_{7}$, bovine serum albumin, butylated hydroxytoluene (BHT), 1-methyl-2-phenylindole, tetramethoxypropane, streptomycin sulfate, guanidine hydrochloride, 2,4-dinitrophenylhydrazine (DNPH), xanthine, xanthine oxidase, nitroblue tetrazolium (NBT), glutathione reduced form (GSH), glutathione oxidized form (GSSG), GR, GST, 1-chloro-2,4-dinitrobenzene (CDNB), dimethyl sulfoxide (DMSO), nicotinamide adenine dinucleotide phosphate reduced form (NADPH), $\mathrm{N}$-(2-hydroxyethyl) piperazine- $\mathrm{N}^{\prime}$-(2-ethanesulfonic acid) (HEPES), adenosine diphosphate (ADP), potassium succinate, rotenone, sodium glutamate, sodium malate, carbonyl cyanide m-chlorophenylhydrazone (CCCP), decylubiquinone, nicotinamide adenine dinucleotide reduced form (NADH), ethylene glycol tetraacetic acid (EGTA), 3-(N-morpholino) propanesulfonic acid (MOPS), potassium cyanide $(\mathrm{KCN})$, antimycin A, safranin $\mathrm{O}$, sucrose, and paraformaldehyde were purchased from Sigma-Aldrich (St. Louis, MO, USA). Commercial kits to measure alanine aminotransferase (ALT), aspartate aminotransferase (AST), lactate dehydrogenase (LDH), and alkaline phosphatase (ALP) were from ELITechGroup (Sées, France). Monochlorobimane was purchased from Fluka (Schnelldorf, Germany). Potassium phosphate monobasic $\left(\mathrm{KH}_{2} \mathrm{PO}_{4}\right)$, sodium phosphate dibasic $\left(\mathrm{Na}_{2} \mathrm{HPO}_{4}\right)$, trichloroacetic acid (TCA), hydrogen peroxide $\left(\mathrm{H}_{2} \mathrm{O}_{2}\right)$, methanol, high-performance liquid chromatography- (HPLC-) grade acetonitrile, and ethyl acetate were acquired from J. T. Baker (Xalostoc, Edo. Mex, México). Tris, acrylamide and bis $\mathrm{N}, \mathrm{N}^{\prime}$ methylene bis acrylamide were purchased from Bio-Rad Laboratories (Hercules, CA, USA). Lauryl sulfate sodium salt (SDS) and calcium chloride were acquired from Research Organics, Inc. (Cleveland, $\mathrm{OH}$, USA). Arsenazo III was purchased from ICN Biomedicals Inc. (Aurora, OH, USA). Aminoacetic acid was obtained from Química Meyer (Mexico, DF, Mexico). Cyclosporine A (CsA) was purchased from Enzo Life Sciences (Farmingdale, NY, USA). Anti-cytochrome c [7H8.2C12] (ab13575) antibody was acquired from Abcam (Cambridge, MA, USA), anti-adenine nucleotide translocator (ANT) 1/2 (N-19) (sc-9299) and rabbit anti-mouse IgG-horseradish peroxidase (HRP, sc-358914) antibodies were purchased from Santa Cruz Biotechnology (Santa Cruz, CA, USA). All other reagents and chemicals used were of the highest grade of purity commercially available.

2.2. Experimental Design. Male Wistar rats weighing $150-$ $200 \mathrm{~g}$ were used along the study. Curcumin was suspended in $0.5 \%$ carboxymethylcellulose and was given by oral gavage a dose of $400 \mathrm{mg} / \mathrm{kg}$ [50], and $\mathrm{K}_{2} \mathrm{Cr}_{2} \mathrm{O}_{7}$ was dissolved in saline solution and given via intraperitoneal (i.p.) at a dose of $15 \mathrm{mg} / \mathrm{kg}$ [52]. Six groups of rats were studied ( $n=8 /$ group). (1) Control, injected via i.p. with isotonic saline solution. (2) Curcumin was given daily for 10 days. (3) $\mathrm{K}_{2} \mathrm{Cr}_{2} \mathrm{O}_{7}(24 \mathrm{~h}$ ), rats received a single injection of $\mathrm{K}_{2} \mathrm{Cr}_{2} \mathrm{O}_{7}$ on day 10 and they were sacrificed $24 \mathrm{~h}$ later. (4) CUR- $\mathrm{K}_{2} \mathrm{Cr}_{2} \mathrm{O}_{7}(24 \mathrm{~h}$ ), curcumin was given daily for 10 days and $\mathrm{K}_{2} \mathrm{Cr}_{2} \mathrm{O}_{7}$ was injected on day 10; rats were sacrificed $24 \mathrm{~h}$ later. (5) $\mathrm{K}_{2} \mathrm{Cr}_{2} \mathrm{O}_{7}(48 \mathrm{~h})$, rats 
were injected with a single injection of $\mathrm{K}_{2} \mathrm{Cr}_{2} \mathrm{O}_{7}$ on day 9 and they were sacrificed $48 \mathrm{~h}$ later. (6) CUR- $\mathrm{K}_{2} \mathrm{Cr}_{2} \mathrm{O}_{7}(48 \mathrm{~h})$, curcumin was administered for 10 days and $\mathrm{K}_{2} \mathrm{Cr}_{2} \mathrm{O}_{7}$ was injected on day 9; rats were sacrificed $48 \mathrm{~h}$ later. Animals were anesthetized and blood was obtained via abdominal aorta at room temperature on day 11 . Blood plasma was separated and stored at $4^{\circ} \mathrm{C}$ until the activity of ALT, AST, LDH, and ALP was measured using commercial kits. Livers were dissected out, cleaned, and weighted, obtaining samples for histological analyses and for measurement of oxidative stress markers and activity of the antioxidant enzymes SOD, CAT, GPx, GR, and GST. Liver samples were removed to isolate mitochondria in order to determine oxidative stress markers, activity of antioxidant enzymes, oxygen consumption and the activity of NADH:ubiquinone oxidoreductase (respiratory complex I), mitochondrial permeability transition, and cytochrome (cyt c) release. All procedures were made to minimize animal suffering and were approved by the Local Ethical Committee (FQ/CICUAL/036/12). Experimental protocols followed the guidelines of Norma Oficial Mexicana for the use and care of laboratory animals (NOM-062-ZOO-1999) and for disposal of biological residues (NOM-087-SEMARNAT-SSA1-2002).

2.3. Histological Studies. Liver slices of $0.5 \mathrm{~cm}$ width were fixed by immersion in $4 \%$ paraformaldehyde, dehydrated, and embedded in paraffin. Thin sections of $3 \mu \mathrm{m}$ were stained with hematoxylin and eosin and were examined under light microscope Leica (Cambridge, UK) [53]. The histological profiles of seven fields 100X randomly selected per rat (3-4 rats per group) were recorded, the number of necrotic hepatocytes (shrinking cells with condensed acidophilic cytoplasm and pyknotic or fragmented nucleus), was counted ( $n=500-$ 800 hepatocytes), and the percentage of damaged cells was obtained.

\subsection{Markers of Oxidative Damage and Activity of Antioxidant} Enzymes in Liver Homogenates. Liver was homogenized in a Brinkmann Polytron Model PT 2000 (Westbury, NY, USA) in cold potassium phosphate buffer. The homogenates were centrifuged and the supernatant was separated to measure oxidative stress markers and the activity of antioxidant enzymes. Protein concentration was measured according to the method described by Lowry et al. [54]. The content of malondialdehyde (MDA), an important toxic byproduct of lipid peroxidation, was measured by the reaction with 1-methyl-2-phenylindole, according to Chirino et al. [55]. Protein carbonyl content, a relatively stable marker of protein oxidation by ROS, was measured by their reactivity with $\mathrm{DNPH}$ to form protein hydrazones, as previously described by Maldonado et al. [56]. GSH content was evaluated by following the formation of a fluorescent adduct between GSH and monochlorobimane in a reaction catalyzed by GST [57]. CAT activity was assayed by a method based on the decomposition of $\mathrm{H}_{2} \mathrm{O}_{2}$ by CAT contained in the samples [58]. SOD activity was assayed by measuring the inhibition of NBT reduction to formazan at $560 \mathrm{~nm}$ [59]. GPx activity was assayed spectrophotometrically at $340 \mathrm{~nm}$ in a mixture assay containing $\mathrm{GSH}, \mathrm{H}_{2} \mathrm{O}_{2}, \mathrm{GR}$, and $\mathrm{NADPH}$ [60]. GR activity was assayed by using GSSG as substrate and measuring the disappearance of NADPH at $340 \mathrm{~nm}$ [61]. GST activity was assayed in a mixture containing GSH and CDNB [62].

2.5. Studies in Isolated Mitochondria. Liver was removed from rats, washed, and minced in isolation buffer before being homogenized. Mitochondria were obtained by differential centrifugation, and the protein content was measured [63]. Markers of oxidative damage and activity of antioxidant enzymes were measured as previously described in Section 2.4. Oxygen consumption was measured using a Clark type oxygen electrode (Yellow Springs Instruments, Yellow Springs, OH, USA). State 4 respiration was evaluated in the presence of succinate plus rotenone or with sodium glutamate and sodium malate. State 3 respiration was stimulated by the addition of ADP. Respiratory control index (RCI) was calculated as the ratio state $3 /$ state 4 . Uncoupled respiration was measured by adding CCCP; phosphorylation efficiency (ADP/O ratio) was calculated from the added amount of ADP and total amount of oxygen consumed during state 3 [64]. The activity of the respiratory complex I was measured by following the decrease in absorbance due to oxidation of $\mathrm{NADH}$ to $\mathrm{NAD}^{+}$at $340 \mathrm{~nm}$ in an assay mixture containing decylubiquinone antimycin $\mathrm{A}, \mathrm{KCN}$, and of mitochondrial protein [65]. Permeability transition pore (PTP) opening was evaluated by measuring swelling which was assessed by changes in absorbance of the suspension at $540 \mathrm{~nm}$, after the addition of $50 \mu \mathrm{M} \mathrm{Ca}^{2+}$ [66]. Membrane potential dissipation was evaluated by safranin $\mathrm{O}$ absorbance changes at $525-575 \mathrm{~nm}$; the reaction was initiated by adding $50 \mu \mathrm{M} \mathrm{Ca}{ }^{2+}$ [67]. $\mathrm{Ca}^{2+}$ retention was determined by the arsenazo III absorbance changes at $675-685 \mathrm{~nm}$, after the addition of $50 \mu \mathrm{M} \mathrm{Ca}^{2+}$ [68]. These assays were effectuated in the presence or absence of CsA. To assess cytochrome c (cyt c) release, mitochondria were incubated with $50 \mu \mathrm{M} \mathrm{Ca}^{2+}$ with or without CsA for $10 \mathrm{~min}$ and pelleted by centrifugation. Released cyt $c$ in the supernatant fractions and retained cyt $c$ in pellets were analyzed by immunoblotting with anti-cyt c $(1: 2,500)$ as described by Zazueta et al. [69]. Adenine nucleotide translocator (ANT, 1:1,000) content was determined as the loading marker. Cyt $\mathrm{c}$ and ANT levels were determined by densitometric analysis using the Image Lite Version 3.1.4 software from LI-COR Biosciences (Lincoln, NE, USA).

2.6. Statistical Analysis. Results were expressed as mean \pm standard error of the mean (SEM). Data were analyzed by one-way ANOVA followed by Bonferroni's multiplecomparisons test using Prism 5.0 software (GraphPad, San Diego, CA, USA). A $P$ value $<0.05$ was considered statistically significant.

\section{Results}

3.1. Curcumin Prevents $\mathrm{K}_{2} \mathrm{Cr}_{2} \mathrm{O}_{7}$-Induced Decrease in Body Weight Gain and Increase of Liver Weight and Liver/Body Ratio. Treatment with $\mathrm{K}_{2} \mathrm{Cr}_{2} \mathrm{O}_{7}$ resulted in a significant decrease in body weight gain and a significant increase in liver 


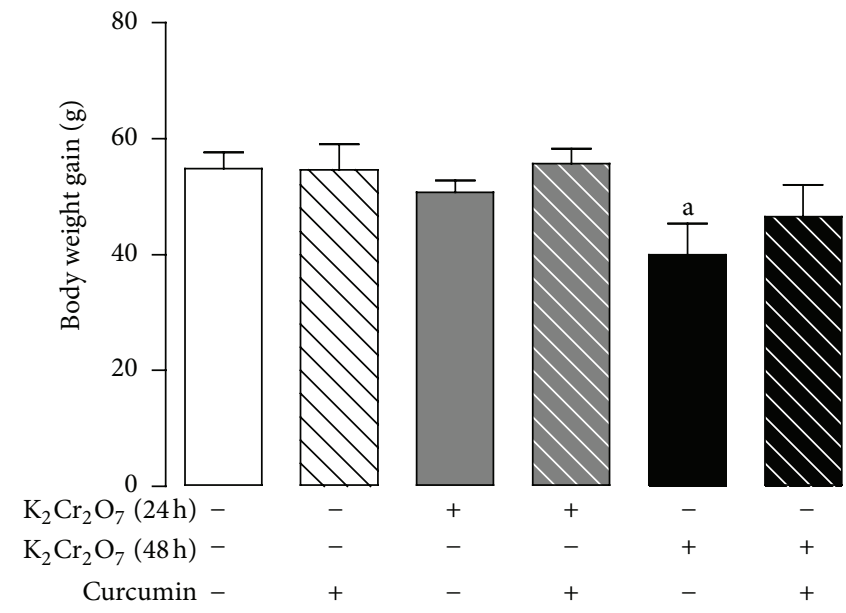

(a)
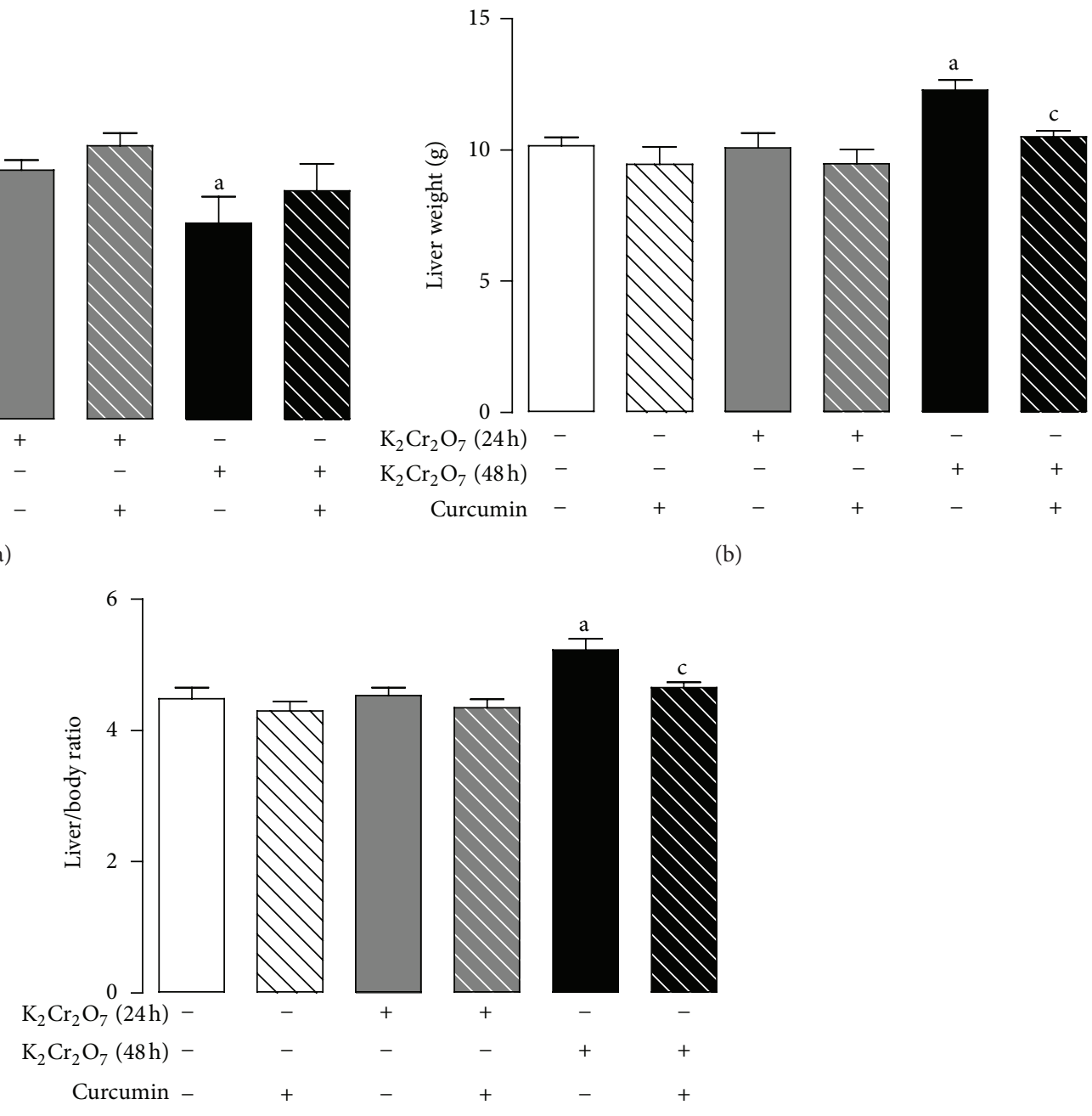

(b)

(c)

FIGURE 1: Effect of curcumin on body and liver weight of rats treated with $\mathrm{K}_{2} \mathrm{Cr}_{2} \mathrm{O}_{7}$. (a) Body weight gain, (b) liver weight, and (c) liver/body ratio. Values are mean $\pm \mathrm{SEM}, n=7-8 .{ }^{\mathrm{a}} \mathrm{P}<0.05$ versus control; ${ }^{\mathrm{c}} \mathrm{P}<0.05$ versus $\mathrm{K}_{2} \mathrm{Cr}_{2} \mathrm{O}_{7}(48 \mathrm{~h})$.

weight and liver/body ratio at $48 \mathrm{~h}$ (Figure 1). Pretreatment with curcumin significantly prevented these effects (Figure 1).

3.2. Curcumin Prevents the $\mathrm{K}_{2} \mathrm{Cr}_{2} \mathrm{O}_{7}$-Induced Increase in the Plasma Activity of ALT, AST, LDH, and ALP. Rats treated with $\mathrm{K}_{2} \mathrm{Cr}_{2} \mathrm{O}_{7}$ exhibited a significant increase in plasma AST, ALT, and LDH activities at 24 and $48 \mathrm{~h}$ compared to control (Figure 2). Curcumin pretreatment significantly prevented the increase in the activity of AST, ALT, and LDH (Figure 2). The $\mathrm{K}_{2} \mathrm{Cr}_{2} \mathrm{O}_{7}$-induced increase in the activity of ALP at $48 \mathrm{~h}$ was prevented by curcumin (Figure 2).

3.3. Curcumin Prevents the $\mathrm{K}_{2} \mathrm{Cr}_{2} \mathrm{O}_{7}$-Induced Histological Damage. Control and curcumin-treated groups presented normal hepatic structure, characterized by polygonal-shape hepatocytes with well-defined boundaries, slight staining acidophilic cytoplasm with large and centrally located nucleus with dispersed chromatin; some binucleated cells were also observed (Figures 3(a) and 3(d)). Treatment with $\mathrm{K}_{2} \mathrm{Cr}_{2} \mathrm{O}_{7}$ generated focal centrolobular hepatocytes death $24 \mathrm{~h}$ and $48 \mathrm{~h}$, in a time-dependent fashion (Figures 3(b) and 3(c)); these cells showed extensive cytoplasmic vacuolation with pyknotic nucleus. In contrast, curcumin-pretreated groups showed almost normal histology; only the CUR- $\mathrm{K}_{2} \mathrm{Cr}_{2} \mathrm{O}_{7}$ group at $48 \mathrm{~h}$ presented occasional injured hepatocytes (Figures 3(e) and 3(f)). These features were confirmed by the quantification of damaged hepatocytes, which revealed that curcumin pretreatment prevented the $\mathrm{K}_{2} \mathrm{Cr}_{2} \mathrm{O}_{7}$-induced significant increase in hepatocytes damage at 24 and $48 \mathrm{~h}$ of about $15 \%$ and $30 \%$, respectively (Figure $3(\mathrm{~g})$ ).

3.4. Curcumin Ameliorates $\mathrm{K}_{2} \mathrm{Cr}_{2} \mathrm{O}_{7}$-Induced Liver Oxidative Damage. Curcumin pretreatment prevents the $\mathrm{K}_{2} \mathrm{Cr}_{2} \mathrm{O}_{7}$ induced oxidative damage, which was made evident by the increase in the levels of MDA and protein carbonyl and a decrease in the levels of GSH at $48 \mathrm{~h}$ (Figure 4). In addition, $\mathrm{K}_{2} \mathrm{Cr}_{2} \mathrm{O}_{7}$ induced an increase of MDA levels at $24 \mathrm{~h}$ that was prevented by curcumin pretreatment (Figure 4). 


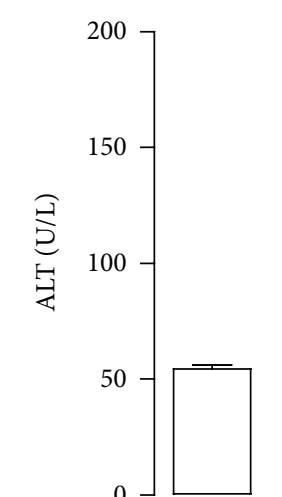

$\mathrm{K}_{2} \mathrm{Cr}_{2} \mathrm{O}_{7}(24 \mathrm{~h})-$ $\mathrm{K}_{2} \mathrm{Cr}_{2} \mathrm{O}_{7}(48 \mathrm{~h})-$

Curcumin -

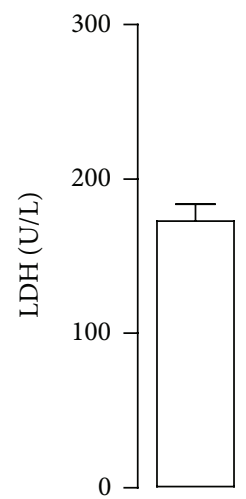

$\mathrm{K}_{2} \mathrm{Cr}_{2} \mathrm{O}_{7}(24 \mathrm{~h})-$

$\mathrm{K}_{2} \mathrm{Cr}_{2} \mathrm{O}_{7}(48 \mathrm{~h})-$

Curcumin -

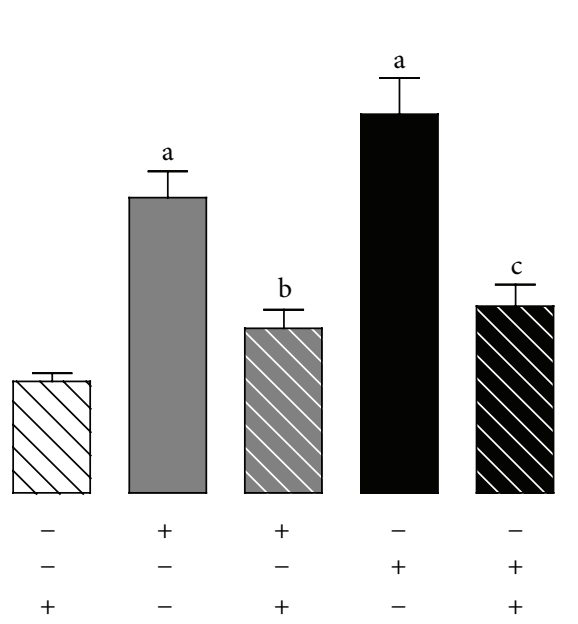

(a)

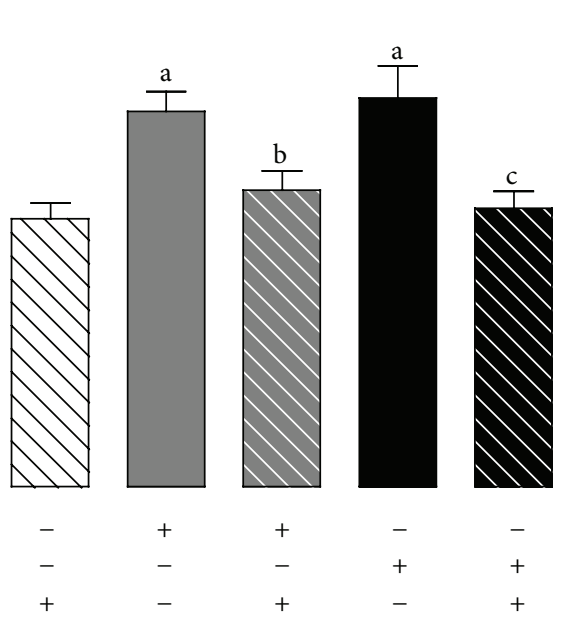

(c)

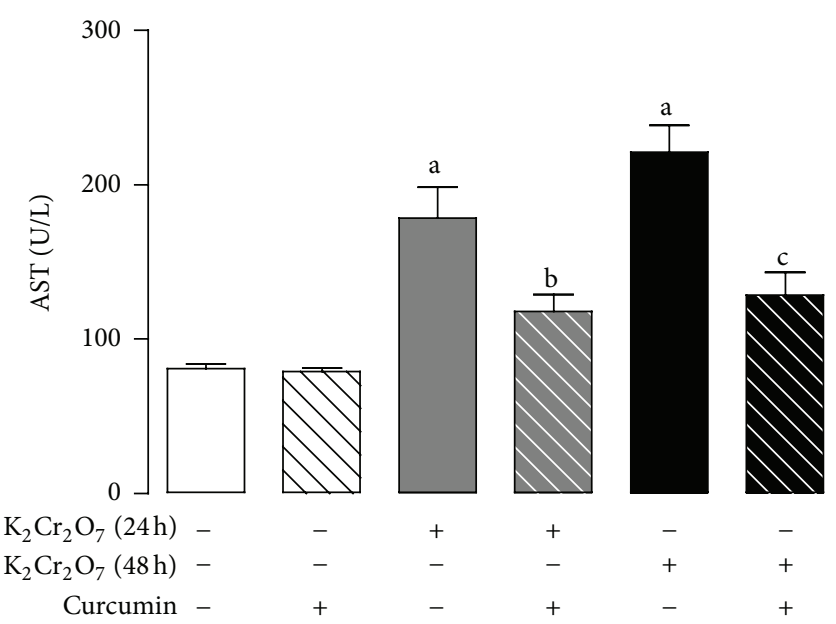

(b)

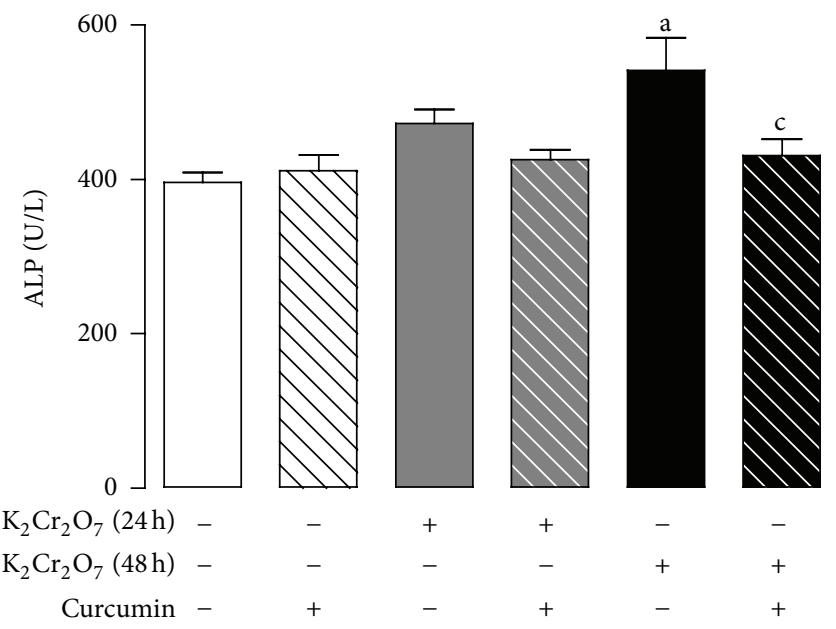

(d)

FIGURE 2: Effect of curcumin on the activity of (a) alanine aminotransferase (ALT), (b) aspartate aminotransferase (AST), (c) lactate dehydrogenase (LDH), and (d) alkaline phosphatase (ALP) in plasma of rats treated with $\mathrm{K}_{2} \mathrm{Cr}_{2} \mathrm{O}_{7}$. Values are mean \pm SEM, $n=5-8$. ${ }^{\mathrm{a}} \mathrm{P}<0.05$ versus control; ${ }^{\mathrm{b}} \mathrm{P}<0.05$ versus $\mathrm{K}_{2} \mathrm{Cr}_{2} \mathrm{O}_{7}(24 \mathrm{~h}){ }^{\mathrm{c}} \mathrm{P}<0.05$ versus $\mathrm{K}_{2} \mathrm{Cr}_{2} \mathrm{O}_{7}(48 \mathrm{~h})$.

The $\mathrm{K}_{2} \mathrm{Cr}_{2} \mathrm{O}_{7}$-induced increase in protein carbonyl content and the decrease in GSH content at $24 \mathrm{~h}$ did not reach statistical significance (Figure 4).

3.5. Curcumin Prevents the $\mathrm{K}_{2} \mathrm{Cr}_{2} \mathrm{O}_{7}$-Induced Decrease in the Activity of Hepatic Antioxidant Enzymes. $\mathrm{K}_{2} \mathrm{Cr}_{2} \mathrm{O}_{7}$ reduced significantly the activity of the antioxidant enzymes SOD, CAT, GPx, GR, and GST at $48 \mathrm{~h}$ and that of GPx at $24 \mathrm{~h}$ that was prevented by curcumin (Figure 5). The $\mathrm{K}_{2} \mathrm{Cr}_{2} \mathrm{O}_{7}$ induced decrease in the activity of CAT and GST on $24 \mathrm{~h}$ was not prevented by curcumin pretreatment (Figure 5).

3.6. Curcumin Prevents $\mathrm{K}_{2} \mathrm{Cr}_{2} \mathrm{O}_{7}$-Induced Oxidative Damage and Decrease in the Activity of Antioxidant Enzymes in Isolated Hepatic Mitochondria. Curcumin prevented the significant increase in $\mathrm{K}_{2} \mathrm{Cr}_{2} \mathrm{O}_{7}$-induced lipid peroxidation and protein carbonyl content in hepatic mitochondria at $48 \mathrm{~h}$. Besides, $\mathrm{K}_{2} \mathrm{Cr}_{2} \mathrm{O}_{7}$ produced a significant decrease of $\mathrm{GSH}$ content at 24 and $48 \mathrm{~h}$. These changes were effectively prevented by curcumin pretreatment (Figure 6). In addition, curcumin pretreatment prevented the $\mathrm{K}_{2} \mathrm{Cr}_{2} \mathrm{O}_{7}$-induced decrease in the activity of GPx and GST at $24 \mathrm{~h}$ and that of SOD, CAT, GPx, $\mathrm{GR}$, and GST at $48 \mathrm{~h}$ (Figure 7 ).

3.7. Curcumin Protects against Mitochondrial Dysfunction Induced by $\mathrm{K}_{2} \mathrm{Cr}_{2} \mathrm{O}_{7}$. Curcumin prevented the $\mathrm{K}_{2} \mathrm{Cr}_{2} \mathrm{O}_{7^{-}}$ induced decrease in mitochondrial respiration evaluated by state 3 and respiratory control index at $24 \mathrm{~h}$ and $48 \mathrm{~h}$ using malate/glutamate as substrate (Figure 8 ). State 4 of respiration remained unchanged in all the studied groups (Figure 8). Curcumin also prevented the $\mathrm{K}_{2} \mathrm{Cr}_{2} \mathrm{O}_{7}$-induced decrease in the $\mathrm{ADP} / \mathrm{O}$ ratio at $48 \mathrm{~h}$ (Figure 8 ). The prevention by curcumin of $\mathrm{K}_{2} \mathrm{Cr}_{2} \mathrm{O}_{7}$-induced decrease in uncoupled respiration was not significative (Figure 8 ). The changes observed using succinate as substrate were less marked. No changes were observed at $24 \mathrm{~h}$; at $48 \mathrm{~h}$ it was found that $\mathrm{K}_{2} \mathrm{Cr}_{2} \mathrm{O}_{7}$ 


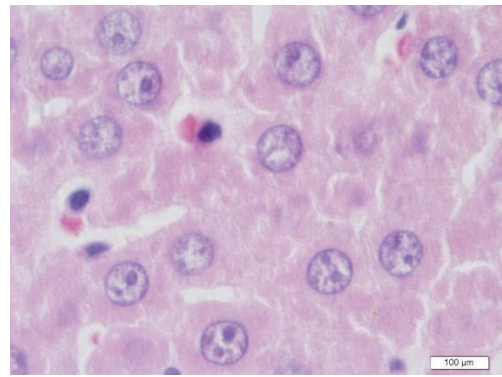

(a)

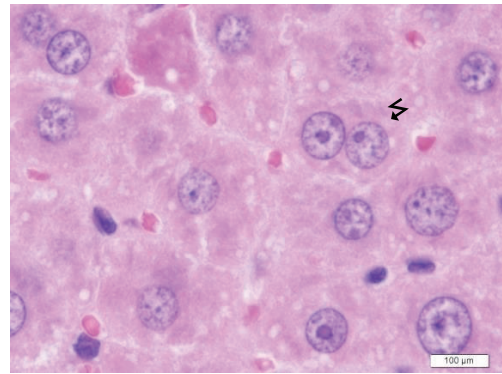

(d)

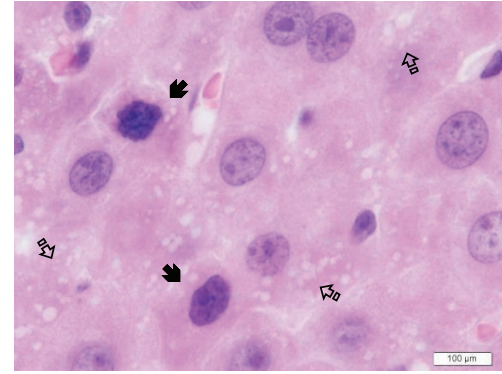

(b)

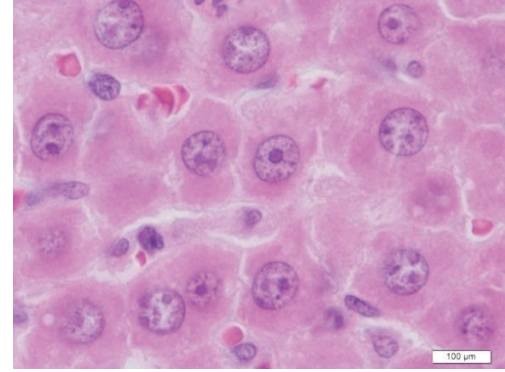

(e)

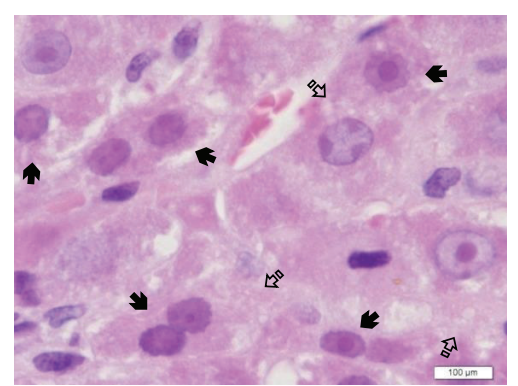

(c)

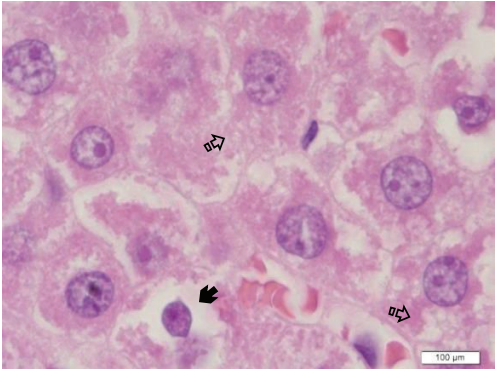

(f)

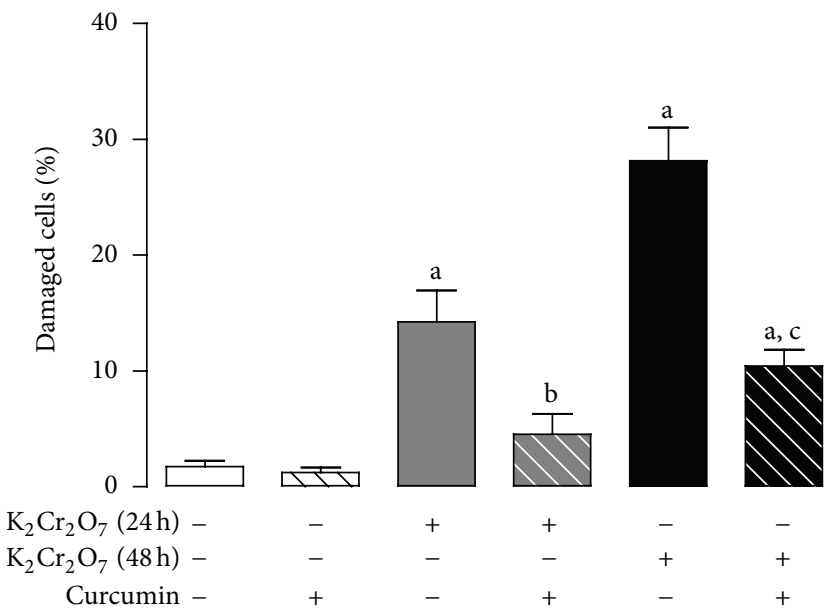

(g)

FIGURE 3: Representative histopathology in rats treated with curcumin, $\mathrm{K}_{2} \mathrm{Cr}_{2} \mathrm{O}_{7}$-or both. (a) Control animal that received only the vehicle show normal hepatic architecture. (b) Rat liver section after one day or two days (c) of $\mathrm{K}_{2} \mathrm{Cr}_{2} \mathrm{O}_{7}$ administration; there are injured hepatocytes with nuclear condensation (pyknosis) and cytoplasmic vacuolization (arrows), as well as regenerative binucleated hepatocytes. (d) In contrast, administration of curcumin alone did not produce histological damage. (e) Rat treated with curcumin after one day of $\mathrm{K}_{2} \mathrm{Cr}_{2} \mathrm{O}_{7}$ administration shows normal liver histology. (f) Liver section after two days of $\mathrm{K}_{2} \mathrm{Cr}_{2} \mathrm{O}_{7}$ administration in animal pretreated with curcumin exhibited mild cytoplasmic vacuolation without pyknosis and binucleated regenerative hepatocytes (all micrographs H/E, magnification 1000X). (g) Quantitative morphometry shows significant liver protection in groups pretreated with curcumin. Values are mean $\pm \mathrm{SEM}, n=3-4$. ${ }^{\mathrm{a}} \mathrm{P}<0.05$ versus control; ${ }^{\mathrm{b}} \mathrm{P}<0.05$ versus $\mathrm{K}_{2} \mathrm{Cr}_{2} \mathrm{O}_{7}(24 \mathrm{~h}) ;{ }^{\mathrm{c}} \mathrm{P}<0.05$ versus $\mathrm{K}_{2} \mathrm{Cr}_{2} \mathrm{O}_{7}(48 \mathrm{~h})$.

induced a decrease in state 3 and in uncoupled respiration, which were not significantly prevented by curcumin (Table 1 ). No changes were observed in respiratory control index, $\mathrm{ADP} / \mathrm{O}$ ratio, and in state 4 (Table 1$)$. All these data led us to analyze the activity of respiratory complex I.

3.8. Curcumin Prevents the $\mathrm{K}_{2} \mathrm{Cr}_{2} \mathrm{O}_{7}$-Induced Decrease in the Respiratory Complex I Activity. $\mathrm{K}_{2} \mathrm{Cr}_{2} \mathrm{O}_{7}$ induced a significative decrease in the activity of respiratory complex I at
$24 \mathrm{~h}$ and $48 \mathrm{~h}$ that was effectively prevented by curcumin pretreatment (Figure 9).

3.9. Curcumin Ameliorates the $\mathrm{K}_{2} \mathrm{Cr}_{2} \mathrm{O}_{7}$-Induced Membrane PTP Opening. Curcumin reduced the $\mathrm{K}_{2} \mathrm{Cr}_{2} \mathrm{O}_{7}$-induced mitochondrial permeability transition determined by matrix swelling, membrane potential changes, and $\mathrm{Ca}^{2+}$ retention at 24 and $48 \mathrm{~h}$. Isolated mitochondria from $\mathrm{K}_{2} \mathrm{Cr}_{2} \mathrm{O}_{7^{-}}$treated rats presented a fast and considerable swelling after 


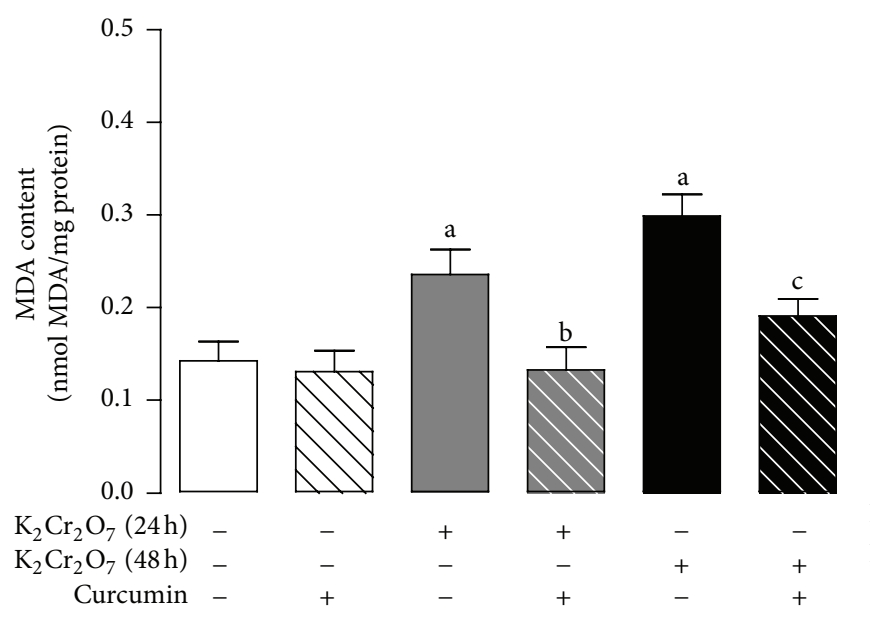

(a)

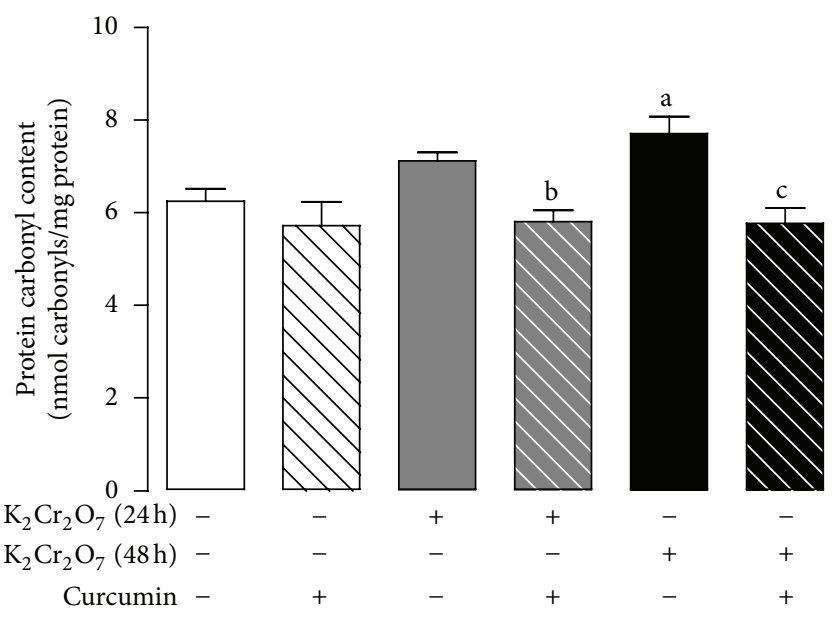

(b)

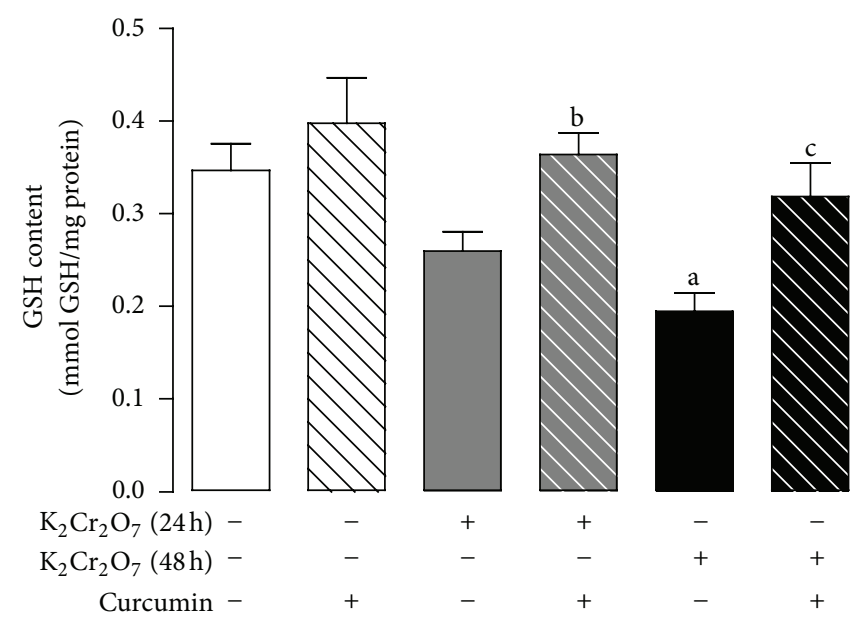

(c)

FIGURE 4: Effect of curcumin on the liver content of oxidative stress markers of rats treated with $\mathrm{K}_{2} \mathrm{Cr}_{2} \mathrm{O}_{7}$. (a) MDA content, (b) protein carbonyl content, and (c) GSH content. Values are mean \pm SEM, $n=5-6 .{ }^{a} P<0.05$ versus control; ${ }^{\text {b }} P<0.05$ versus $_{2} \mathrm{Kr}_{2} \mathrm{O}_{7}(24 \mathrm{~h})$; ${ }^{\mathrm{c}} \mathrm{P}<0.05$ versus $\mathrm{K}_{2} \mathrm{Cr}_{2} \mathrm{O}_{7}(48 \mathrm{~h})$.

TABLE 1: Effect of curcumin pretreatment on $\mathrm{K}_{2} \mathrm{Cr}_{2} \mathrm{O}_{7}$-induced alterations in mitochondrial oxygen consumption using succinate as substrate.

\begin{tabular}{|c|c|c|c|c|c|c|}
\hline & Control & CUR & $\begin{array}{c}\mathrm{K}_{2} \mathrm{Cr}_{2} \mathrm{O}_{7} \\
(24 \mathrm{~h})\end{array}$ & $\begin{array}{c}\text { CUR- } \\
\mathrm{K}_{2} \mathrm{Cr}_{2} \mathrm{O}_{7} \\
(24 \mathrm{~h})\end{array}$ & $\begin{array}{c}\mathrm{K}_{2} \mathrm{Cr}_{2} \mathrm{O}_{7} \\
(48 \mathrm{~h})\end{array}$ & $\begin{array}{c}\text { CUR- } \\
\mathrm{K}_{2} \mathrm{Cr}_{2} \mathrm{O}_{7} \\
(48 \mathrm{~h})\end{array}$ \\
\hline \multicolumn{7}{|l|}{ Succinate } \\
\hline State 3 (ngAtO/min/mg protein) & $243 \pm 24$ & $192 \pm 9$ & $169 \pm 24$ & $170 \pm 36$ & $156 \pm 13^{\mathrm{a}}$ & $180 \pm 27$ \\
\hline State 4 (ngAtO/min/mg protein) & $59 \pm 5$ & $48 \pm 2$ & $51 \pm 7$ & $40 \pm 10$ & $49 \pm 4$ & $51 \pm 5$ \\
\hline RCI & $4.1 \pm 0.3$ & $4.0 \pm 0.2$ & $3.5 \pm 0.1$ & $4.3 \pm 0.2$ & $3.2 \pm 0.3$ & $3.5 \pm 0.4$ \\
\hline Uncoupled respiration (ngAtO/min/mg protein) & $396 \pm 34$ & $363 \pm 21$ & $284 \pm 39$ & $269 \pm 63$ & $245 \pm 34^{\mathrm{a}}$ & $269 \pm 18$ \\
\hline $\mathrm{ADP} / \mathrm{O}$ & $1.3 \pm 0.1$ & $1.6 \pm 0.1$ & $1.6 \pm 0.1$ & $1.6 \pm 0.2$ & $1.4 \pm 0.2$ & $1.4 \pm 0.1$ \\
\hline
\end{tabular}

Values are mean \pm SEM, $n=4-5$. CUR: curcumin; RCI: respiratory control index. ${ }^{\mathrm{a}} P<0.05$ versus control.

adding $50 \mu \mathrm{M} \mathrm{Ca}^{2+}$ at 24 and $48 \mathrm{~h}$. Curcumin pretreatment clearly avoided the $\mathrm{K}_{2} \mathrm{Cr}_{2} \mathrm{O}_{7}$-induced mitochondrial swelling (Figure $10(\mathrm{a})$ ). In a similar way, $\mathrm{K}_{2} \mathrm{Cr}_{2} \mathrm{O}_{7}$ treatment sensitizes mitochondria to lose the membrane potential and the capacity of management $\mathrm{Ca}^{2+}$ by inducing PTP opening.
On the contrary, curcumin pretreatment notably attenuates the $\mathrm{K}_{2} \mathrm{Cr}_{2} \mathrm{O}_{7}$-induced membrane potential collapse and $\mathrm{Ca}^{2+}$ release (Figures $10(\mathrm{~b})$ and $10(\mathrm{c})$ ). $\mathrm{K}_{2} \mathrm{Cr}_{2} \mathrm{O}_{7}$-induced PTP opening was prevented by CsA. Mitochondria from control or curcumin-treated rats did not present PTP opening even 


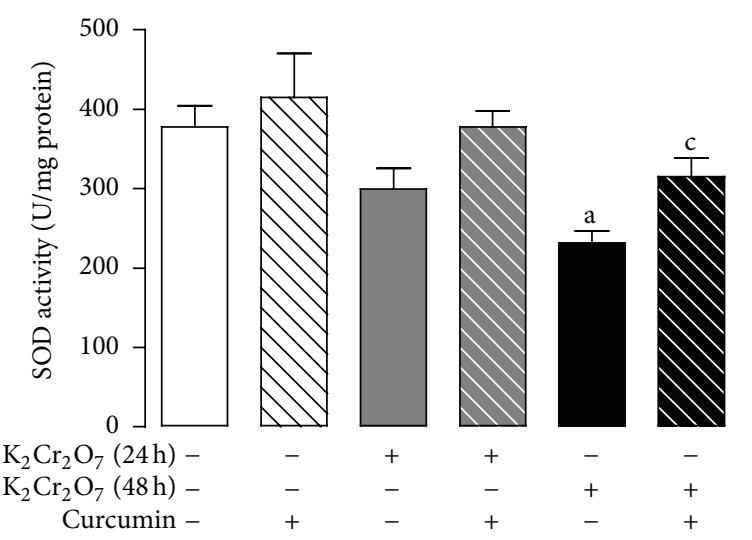

(a)

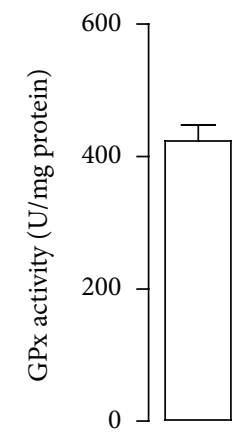

$\mathrm{K}_{2} \mathrm{Cr}_{2} \mathrm{O}_{7}(24 \mathrm{~h})-$ $\mathrm{K}_{2} \mathrm{Cr}_{2} \mathrm{O}_{7}(48 \mathrm{~h})-$

Curcumin -

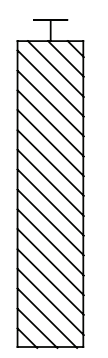

$-$

-
-
+

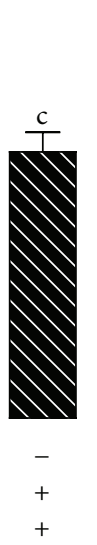

(c)

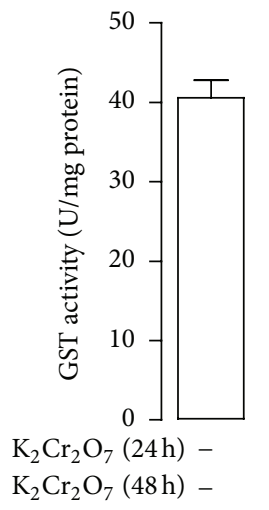

Curcumin -

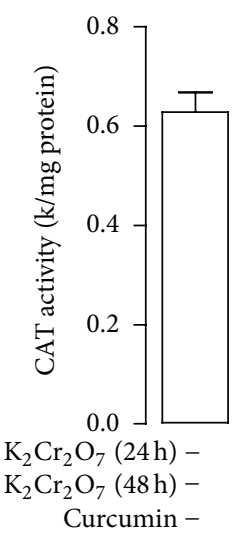

(b)

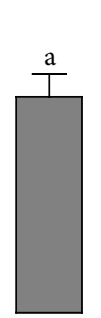

$+$

$-$

$-$
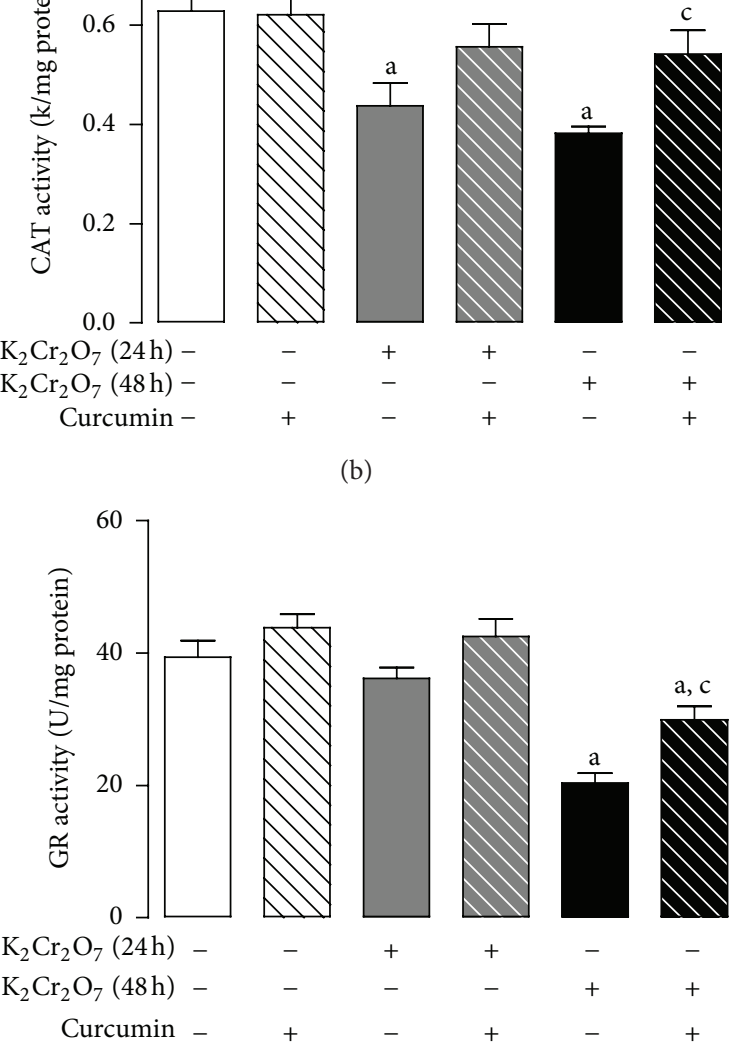

(d)
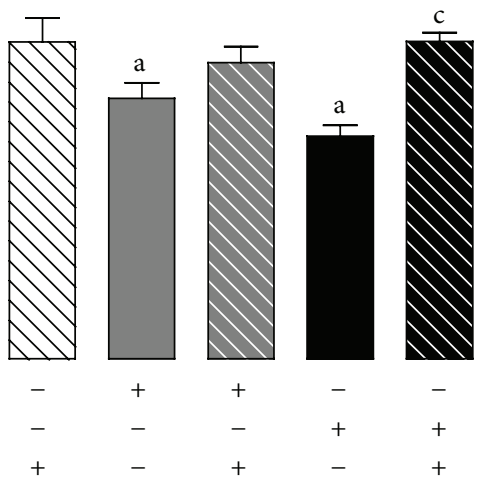

(e)

FIGURE 5: Effect of curcumin on liver activity of antioxidant enzymes activity of rats treated with $\mathrm{K}_{2} \mathrm{Cr}_{2} \mathrm{O}_{7}$. (a) Superoxide dismutase (SOD), (b) catalase (CAT), (c) glutathione peroxidase (GPx), (d) glutathione reductase (GR), and (e) glutathione-S-transferase (GST). Values are mean \pm SEM, $n=5-6 .{ }^{\mathrm{a}} P<0.05$ versus control; ${ }^{\mathrm{b}} \mathrm{P}<0.05$ versus $\mathrm{K}_{2} \mathrm{Cr}_{2} \mathrm{O}_{7}(24 \mathrm{~h}) ;{ }^{\mathrm{c}} \mathrm{P}<0.05$ versus $\mathrm{K}_{2} \mathrm{Cr}_{2} \mathrm{O}_{7}(48 \mathrm{~h})$.

under conditions of $\mathrm{Ca}^{2+}$ overload until the protonophore CCCP was added.

3.10. Curcumin Prevents the $\mathrm{K}_{2} \mathrm{Cr}_{2} \mathrm{O}_{7}$-Induced Cyt C Release. $\mathrm{K}_{2} \mathrm{Cr}_{2} \mathrm{O}_{7}$-induced PTP opening resulted in the release of proapoptotic factor cyt $\mathrm{c}$ to the cytosol at both 24 and $48 \mathrm{~h}$ (Figure 11(a), lanes 3 and 6). CsA abolished the
$\mathrm{K}_{2} \mathrm{Cr}_{2} \mathrm{O}_{7}$-induced cyt $\mathrm{c}$ release (Figure 11(a), lanes 4 and 7). Interestingly, curcumin pretreatment prevents effectively the mitochondrial cyt $\mathrm{c}$ release that was induced by the treatment with $\mathrm{K}_{2} \mathrm{Cr}_{2} \mathrm{O}_{7}$ under conditions of $\mathrm{Ca}^{2+}$ overload (Figure 11(a), lanes 5 and 8). No effects were observed in control and curcumin groups (Figure 11(a), lanes 1 and 2). Densitometric analysis showed that released cyt $\mathrm{c}$ was significantly increased in mitochondria from $\mathrm{K}_{2} \mathrm{Cr}_{2} \mathrm{O}_{7}$-treated 


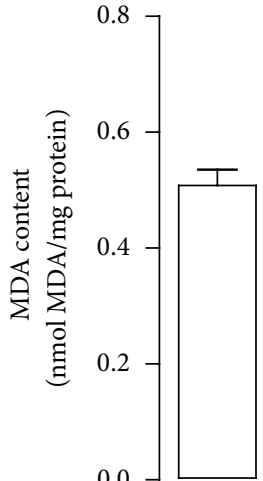

$\mathrm{K}_{2} \mathrm{Cr}_{2} \mathrm{O}_{7}(24 \mathrm{~h})-$

$\mathrm{K}_{2} \mathrm{Cr}_{2} \mathrm{O}_{7}(48 \mathrm{~h})-$

Curcumin -

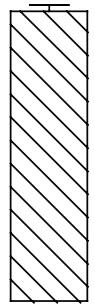

$-$

\begin{abstract}
$-$
\end{abstract}
(a)

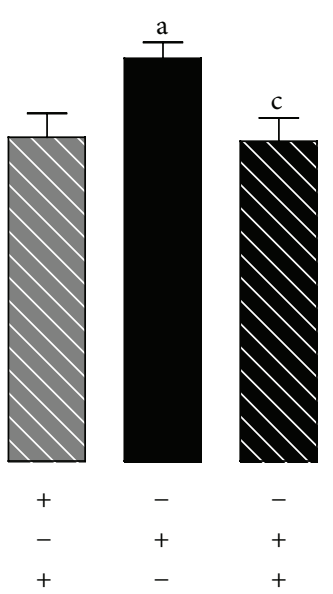

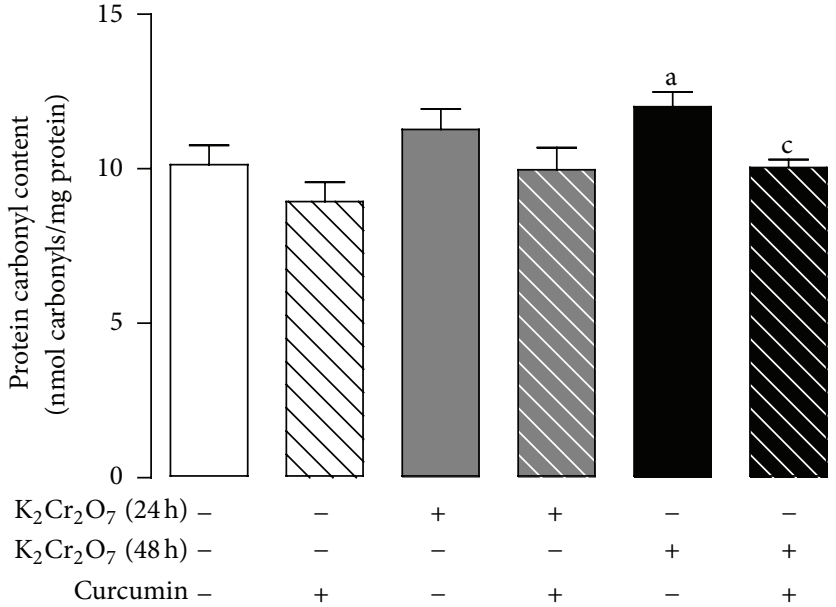

(b)

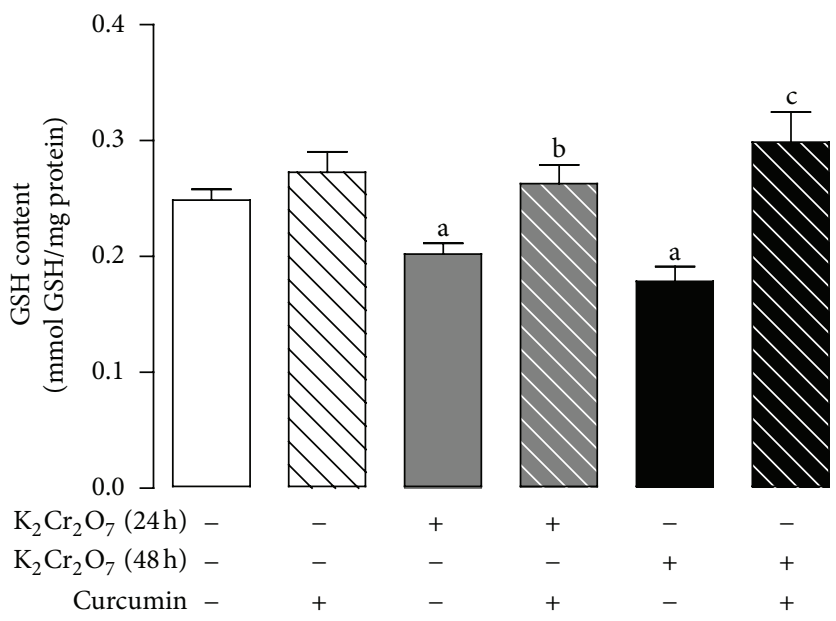

(c)

FiguRE 6: Effect of curcumin on the content of oxidative stress markers in hepatic mitochondria isolated from rats treated with $\mathrm{K}_{2} \mathrm{Cr}_{2} \mathrm{O}_{7}$. (a) MDA, (b) protein carbonyl, and (c) GSH. Values are mean \pm SEM, $n=5-6$. ${ }^{\mathrm{a}} P<0.05$ versus control; ${ }^{\mathrm{b}} P<0.05 \mathrm{versus}_{2} \mathrm{Cr}_{2} \mathrm{O}_{7}(24 \mathrm{~h}$ ); ${ }^{c} P<0.05$ versus $\mathrm{K}_{2} \mathrm{Cr}_{2} \mathrm{O}_{7}(48 \mathrm{~h})$.

rats at 24 and $48 \mathrm{~h}$. Curcumin and CsA prevented the cyt $c$ release from mitochondria (Figure 11(b)). In contrast, retained cyt $c$ in mitochondrial pellets from $\mathrm{K}_{2} \mathrm{Cr}_{2} \mathrm{O}_{7}$-treated rats was significantly diminished at both times while curcumin pretreatment and CsA maintained cyt c levels similar to control (Figure 11(c)). Together, these results indicate that $\mathrm{K}_{2} \mathrm{Cr}_{2} \mathrm{O}_{7}$ lowers the calcium-induced threshold for PTP opening induction and cytochrome $\mathrm{c}$ release.

\section{Discussion}

Experimental models of toxic liver injury are utilized to evaluate the biochemical processes involved in many forms of liver disease and to evaluate the possible pharmacological effects of candidate hepatoprotectants like curcumin [4].

Our data clearly show that curcumin pretreatment effectively prevented $\mathrm{K}_{2} \mathrm{Cr}_{2} \mathrm{O}_{7}$-induced hepatotoxicity. This protective effect was associated to the prevention of
$\mathrm{K}_{2} \mathrm{Cr}_{2} \mathrm{O}_{7}$-induced oxidative damage, decrease in the activity of antioxidant enzymes in both liver homogenates and isolated mitochondria, and impairment in mitochondrial oxygen consumption, respiratory complex I inhibition, and PTP opening. The $\mathrm{K}_{2} \mathrm{Cr}_{2} \mathrm{O}_{7}$-induced hepatotoxicity was evident by the decrease in body weight gain, liver weight, and liver/body ratio, the increase in the plasma activity of ALT, AST, LDH, and ALP, and by the histopathological alterations. Kumar and Roy [70] also found that chromium induced a decrease in body weight gain, liver weight, and liver/body ratio. Increased plasma activity of ALT, AST, and ALP is indicative of hepatocellular damage since the disruption of the plasma membrane leak intracellular enzymes into the bloodstream [71, 72]. Treatment with $\mathrm{K}_{2} \mathrm{Cr}_{2} \mathrm{O}_{7}$ significantly augmented the activity of these enzymes in a time-dependent fashion. $\mathrm{LDH}$ in plasma is a presumptive marker of necrotic lesions in the hepatocytes [73]. Pretreatment with curcumin prevented the increase in the above-mentioned alterations, demonstrating the 


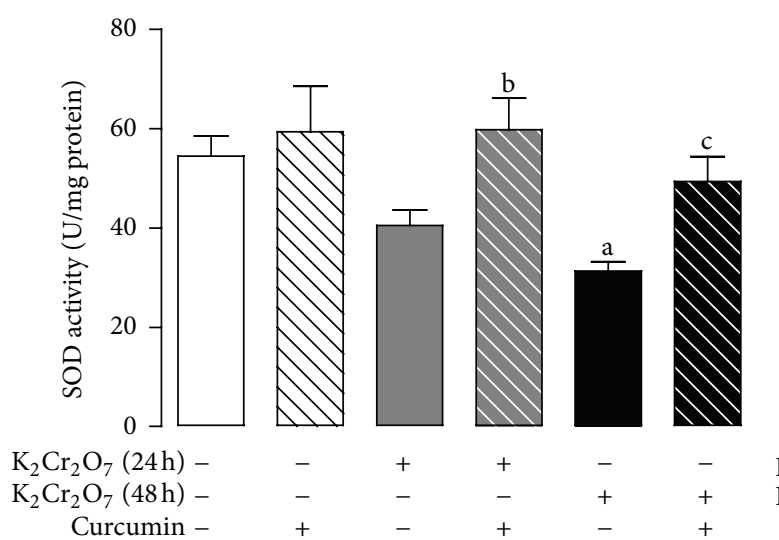

(a)

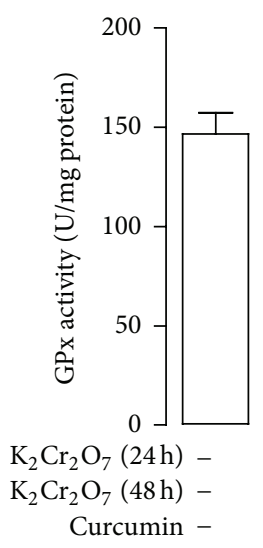

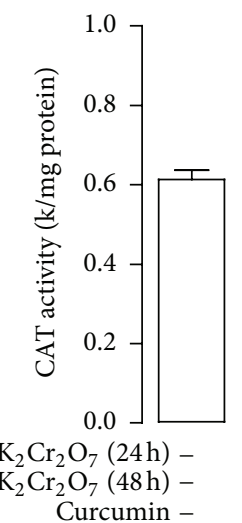
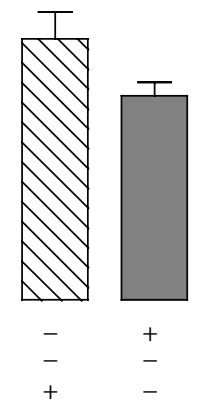

(b)

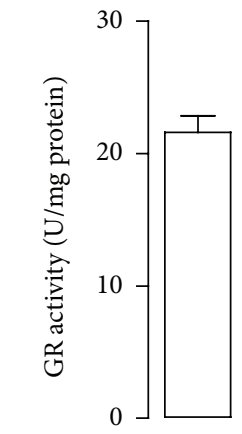

$\mathrm{K}_{2} \mathrm{Cr}_{2} \mathrm{O}_{7}(24 \mathrm{~h})-$ $\mathrm{K}_{2} \mathrm{Cr}_{2} \mathrm{O}_{7}(48 \mathrm{~h})-$ Curcumin -

(c)
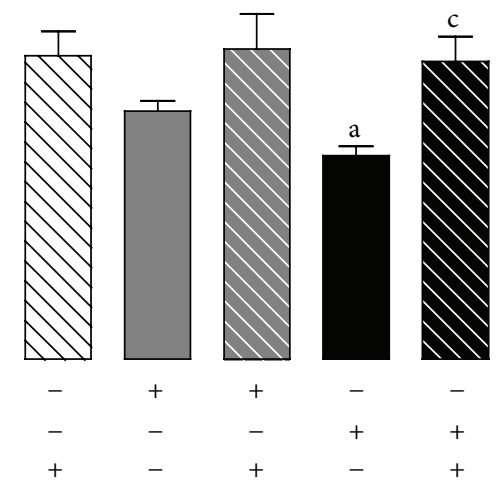

(d)

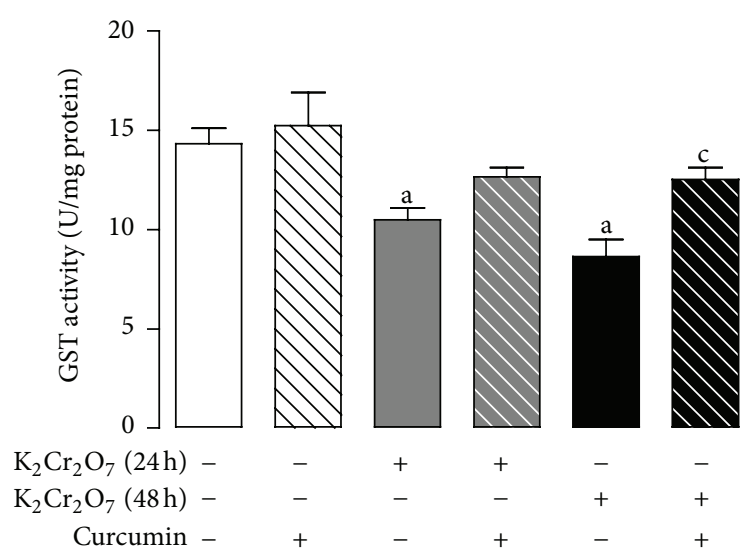

(e)

FIGURE 7: Effect of curcumin on the activity of antioxidant enzymes activity in hepatic mitochondria isolated from rats exposed to $\mathrm{K}_{2} \mathrm{Cr}_{2} \mathrm{O}_{7}$. (a) Superoxide dismutase (SOD), (b) catalase (CAT), (c) glutathione peroxidase (GPx), (d) glutathione reductase (GR), and (e) glutathione$S$-transferase (GST). Values are mean \pm SEM, $n=5-6 .{ }^{\mathrm{a}} \mathrm{P}<0.05$ versus control; ${ }^{\mathrm{b}} \mathrm{P}<0.05$ versus $\mathrm{K}_{2} \mathrm{Cr}_{2} \mathrm{O}_{7}(24 \mathrm{~h}) ;{ }^{\mathrm{c}} \mathrm{P}<0.05$ versus $\mathrm{K}_{2} \mathrm{Cr}_{2} \mathrm{O}_{7}$ (48 h).

hepatoprotective effect of curcumin against the $\mathrm{K}_{2} \mathrm{Cr}_{2} \mathrm{O}_{7^{-}}$ induced damage. These findings are compatible with the results of other studies using curcumin against iron-induced hepatic toxicity [74] or thioacetamide-induced hepatic fibrosis [75]. Histopathological abnormalities were observed in liver of rats treated with $\mathrm{K}_{2} \mathrm{Cr}_{2} \mathrm{O}_{7}$ in a time-dependent fashion that correspond with the increase in the activity of plasma enzymes. The redox alterations caused by oxidative agents like $\mathrm{Cr}(\mathrm{VI})$ compounds have been shown to induce apoptosis and necrosis in hepatocytes and other cells [76]. In this way, the antioxidant curcumin prevented the $\mathrm{K}_{2} \mathrm{Cr}_{2} \mathrm{O}_{7}$-induced structural injury, preserving the normal architecture in liver tissue and saving hepatocytes from ROS. Previous studies have shown that curcumin protects 


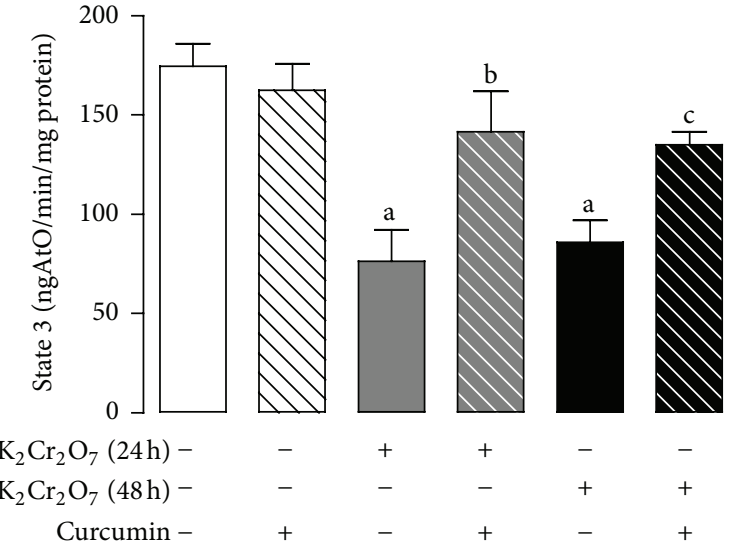

(a)

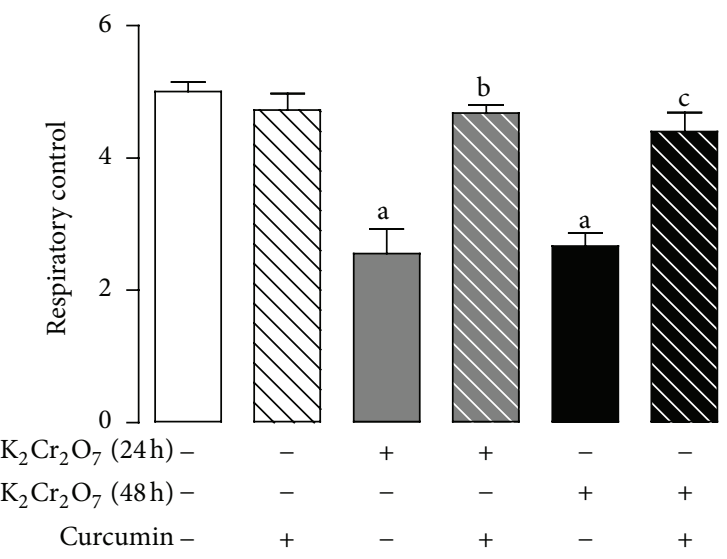

(c)

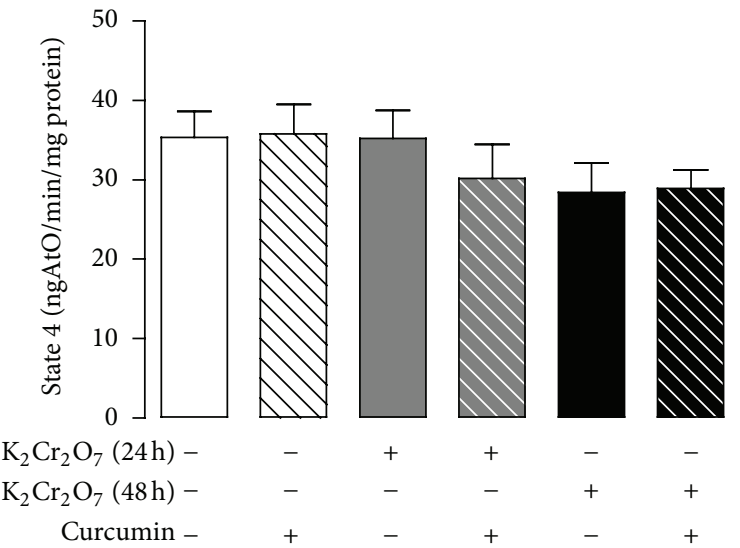

(b)

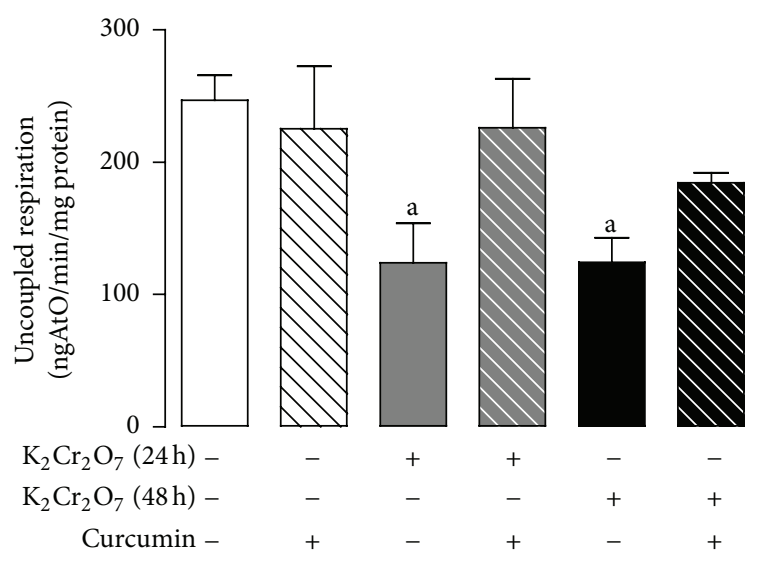

(d)

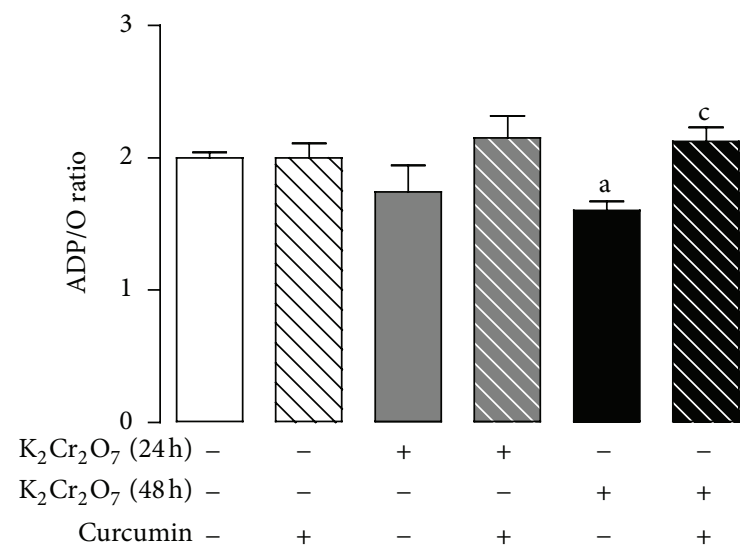

(e)

FIGURE 8: Curcumin prevents $\mathrm{K}_{2} \mathrm{Cr}_{2} \mathrm{O}_{7}$-induced alterations in mitochondrial oxygen consumption using malate/glutamate as substrate. CUR: curcumin; RCI: respiratory control index. Values are mean $\pm \mathrm{SEM}, n=4-5$. ${ }^{\mathrm{a}} \mathrm{P}<0.05$ versus control; ${ }^{\mathrm{b}} \mathrm{P}<0.05 \mathrm{versus}_{2} \mathrm{~K}_{2} \mathrm{O}_{7}(24 \mathrm{~h})$; ${ }^{\mathrm{c}} \mathrm{P}<0.05$ versus $\mathrm{K}_{2} \mathrm{Cr}_{2} \mathrm{O}_{7}(48 \mathrm{~h})$.

against liver histological changes induced by toxins as carbon tetrachloride [17], acetaminophen [77], or cypermethrin [78]. Liver, the primary organ involved in the xenobiotic metabolism, is particularly susceptible to injury, and many reports suggest that chromium is a hepatotoxin [79-82]. Chromium induced-hepatotoxicity may be attenuated by several compounds [83-85]. The antihepatotoxic effects of curcumin against liver injury are well recognized and attributed to its intrinsic antioxidant properties [86-88].

$\mathrm{Cr}(\mathrm{VI})$ induces oxidative stress through enhanced ROS production leading to genomic DNA damage and oxidative deterioration of lipids and proteins. ROS include superoxide 


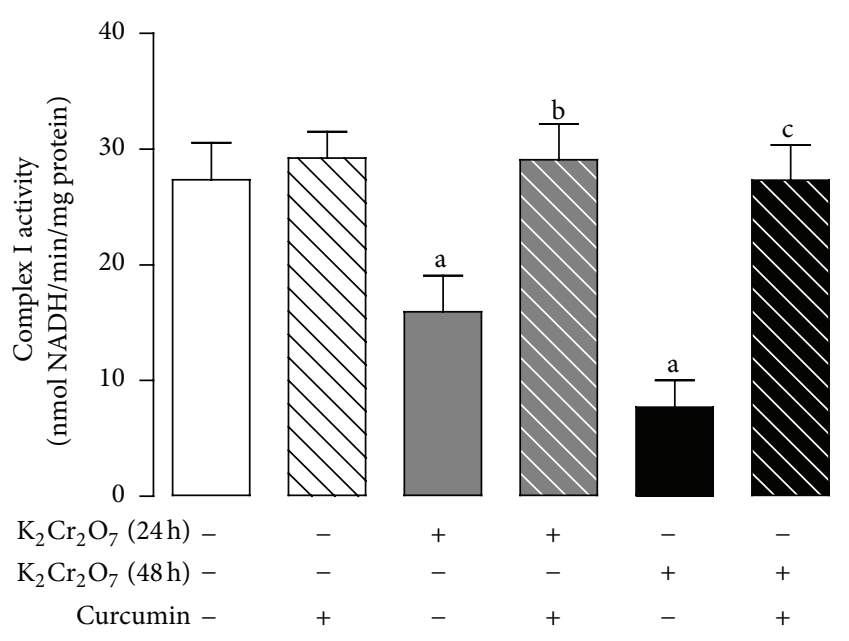

FIGURE 9: Curcumin prevents the $\mathrm{K}_{2} \mathrm{Cr}_{2} \mathrm{O}_{7}$-induced decrease in the activity of mitochondrial complex I. Values are mean \pm SEM, $n=6$ 7. ${ }^{\mathrm{a}} \mathrm{P}<0.05$ versus control; ${ }^{\mathrm{b}} \mathrm{P}<0.05$ versus $\mathrm{K}_{2} \mathrm{Cr}_{2} \mathrm{O}_{7}(24 \mathrm{~h})$; ${ }^{\mathrm{c}} \mathrm{P}<$ 0.05 versus $\mathrm{K}_{2} \mathrm{Cr}_{2} \mathrm{O}_{7}(48 \mathrm{~h})$.

anion radical $\mathrm{O}_{2}{ }^{\cdot-}$, hydrogen peroxide $\left(\mathrm{H}_{2} \mathrm{O}_{2}\right)$, and the highly reactive hydroxyl radical $\left({ }^{\circ} \mathrm{OH}\right)$ [20]. Lipid peroxidation generates a wide variety of end products, including MDA, which is used as a marker of oxidative damage. MDA may damage membrane proteins and lipids [89]. However, the formation of oxidized proteins is one of the highlights of oxidative stress, and the carbonyl groups (aldehydes and ketones) are produced on protein side chains when they are oxidized [90]. The results obtained show clearly that $\mathrm{K}_{2} \mathrm{Cr}_{2} \mathrm{O}_{7}$ increased lipid peroxidation and oxidized proteins reflecting hepatic oxidative damage. Curcumin pretreatment could prevent $\mathrm{K}_{2} \mathrm{Cr}_{2} \mathrm{O}_{7}$-induced oxidative damage because it is considered a bifunctional antioxidant exerting direct effects by scavenging ${ }^{\circ} \mathrm{OH}, \mathrm{O}_{2}{ }^{\cdot-}$, and peroxyl radicals [91] and indirect effects inducing the expression of antioxidant enzymes [92].

GSH is a tripeptide (L- $\gamma$-glutamyl-L-cysteinylglycine) responsible for protection against ROS and other reactive species and detoxification of endogenous and exogenous toxins of an electrophilic nature [93]. Depletion of GSH decreases the antioxidant capacity and leads to oxidative stress $[94,95]$. Rats treated with $\mathrm{K}_{2} \mathrm{Cr}_{2} \mathrm{O}_{7}$ presented low GSH levels in comparison with control, probably due to the oxidative stress induced for the $\mathrm{K}_{2} \mathrm{Cr}_{2} \mathrm{O}_{7}$ exposition. Soudani et al. [42] stated that this reduction in GSH levels might be due to its consumption in the scavenging of free radicals generated by $\mathrm{K}_{2} \mathrm{Cr}_{2} \mathrm{O}_{7}$. Curcumin pretreatment restored $\mathrm{GSH}$ levels, in a similar way to previous reports demonstrating the effectiveness curcumin in the reestablishment of the GSH content in the liver of rats exposed to paracetamol [14] or aflatoxin [96].

Antioxidant enzymes are important protective mechanisms against ROS. SOD catalyses the dismutation of $\mathrm{O}_{2}{ }^{--}$ to $\mathrm{O}_{2}$ and to the less reactive species $\mathrm{H}_{2} \mathrm{O}_{2}$. Peroxides can be degraded by CAT or GPx [97]. GR converts GSSG to GSH by using NADPH whereas GST catalyzes the conjugation of electrophilic species with GSH [98]. In this study,
$\mathrm{K}_{2} \mathrm{Cr}_{2} \mathrm{O}_{7}$ decreased the activity of SOD, CAT, GPx, GR, and GST mainly $48 \mathrm{~h}$ after treatment. This effect may be secondary to decreased enzyme levels (secondary to changes in synthesis or degradation of enzymes) or decreased activity (e.g., by oxidative damage) without changes in enzymes levels [95]. In this context, Kalayarasan et al. [73] postulated that $\mathrm{K}_{2} \mathrm{Cr}_{2} \mathrm{O}_{7}$ produces high levels of $\mathrm{O}_{2}{ }^{--}$which override enzymatic activity in liver tissues. Pretreatment with curcumin reestablished the activity of antioxidant enzymes to normal in animals exposed to $\mathrm{K}_{2} \mathrm{Cr}_{2} \mathrm{O}_{7}$, as has been shown in different curcumin hepatoprotection studies against sodium arsenite [99], acrylonitrile [100], chloroquine [101], or arsenic trioxide [102] toxicity. Besides, Iqbal et al. [5] revealed that curcumin administration increases several cytoprotective enzymes, especially in the liver.

Hepatocytes are normally rich in mitochondria, and each hepatocyte contains about 800 mitochondria occupying about $18 \%$ of the entire liver cell volume [103]. Mitochondria are targets of metal toxicity, and in many cases is related with oxidative stress and mitochondrial dysfunction [104107]. Mitochondria are the main intracellular source of ROS as byproducts of the consumption of molecular oxygen in the electron transport chain and themselves are susceptible to oxidation; however, they possess a very effective antioxidant system $[108,109]$. The experimental results in hepatic mitochondria isolated from rats treated with $\mathrm{K}_{2} \mathrm{Cr}_{2} \mathrm{O}_{7}$ demonstrate an increase in mitochondrial lipids and oxidized proteins, GSH depletion and reduction in the activity of antioxidant enzymes being this effect more consistent after $48 \mathrm{~h}$ of exposition. These results are in relation with previous studies [110, 111]. Moreover, curcumin successfully prevents mitochondrial oxidative damage and the alterations in the antioxidant enzyme activities caused by $\mathrm{K}_{2} \mathrm{Cr}_{2} \mathrm{O}_{7}$. Curcumin can protect rat liver mitochondria from ROS-induced lipid peroxidation and protein oxidation by donating $\mathrm{H}$-atoms from its phenolic and methylenic groups of the $\beta$-diketone moiety [86, 112], augmenting levels of GSH $[113,114]$ or increasing the cytoprotective defenses, in a similar way with other experimental models $[115,116]$.

Oxidative stress leads to mitochondrial dysfunction, decrease in oxygen consumption and ATP production, alterations in calcium homeostasis, oxidation of DNA, proteins, and lipids, PTP opening, modifying of the expression of antioxidant enzymes and enhancing expression, and/or DNA binding of numerous transcription factors [117-119]. Our results showed that liver mitochondria isolated from rats exposed to $\mathrm{K}_{2} \mathrm{Cr}_{2} \mathrm{O}_{7}$ presented alterations in oxygen consumption by decreasing state 3 respiration, RCI, uncoupled respiration and $\mathrm{ADP} / \mathrm{O}$ ratio using malate/glutamate. Negative effects using succinate were less evident, affecting state 3 and uncoupled respiration. These results indicate that $\mathrm{K}_{2} \mathrm{Cr}_{2} \mathrm{O}_{7}$ could damage biomolecules from the electron transport chain, especially complex I. In agreement, $\mathrm{Cr}(\mathrm{VI})$ has shown noxious effects on liver mitochondrial bioenergetics, as a consequence of its oxidizing activity which shunts electrons from electron donors coupled to ATP production, and to the ability of $\mathrm{Cr}$ (III), derived from $\mathrm{Cr}$ (VI) reduction, to form stable complexes with ATP precursors and enzymes involved in the ATP synthesis [46]. Noticeably, 


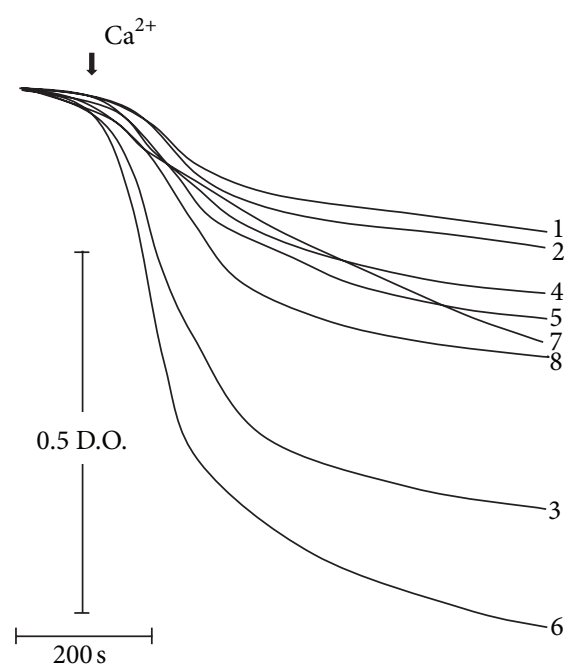

(a)

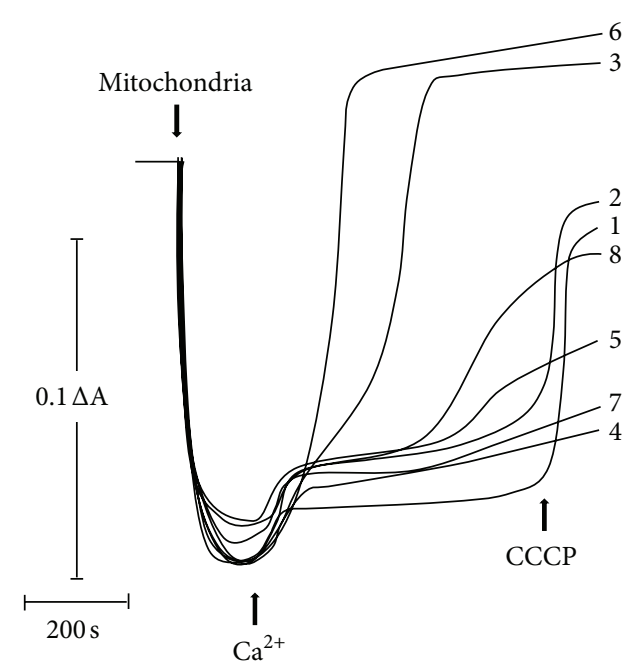

(b)

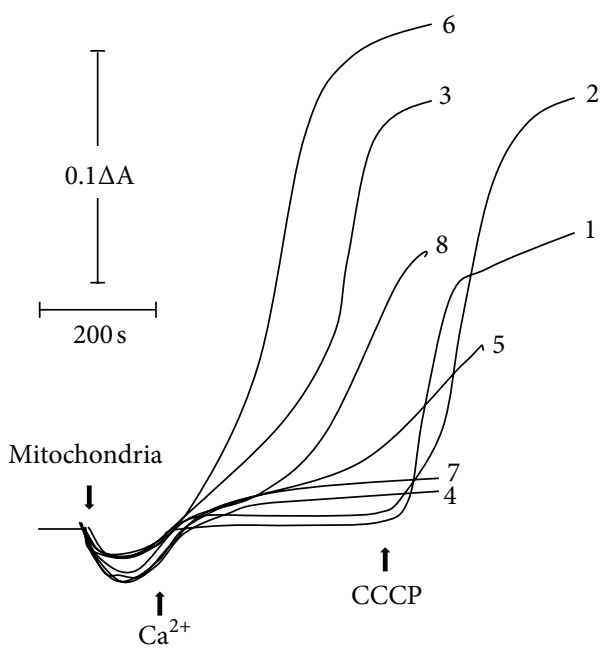
(1) Control
(5) $\mathrm{CUR}+\mathrm{K}_{2} \mathrm{Cr}_{2} \mathrm{O}_{7}(24 \mathrm{~h})$
(2) Curcumin (CUR)
(6) $\mathrm{K}_{2} \mathrm{Cr}_{2} \mathrm{O}_{7}(48 \mathrm{~h})$
(3) $\mathrm{K}_{2} \mathrm{Cr}_{2} \mathrm{O}_{7}(24 \mathrm{~h})$
(7) $\mathrm{K}_{2} \mathrm{Cr}_{2} \mathrm{O}_{7}(48 \mathrm{~h})+\mathrm{CsA}$
(4) $\mathrm{K}_{2} \mathrm{Cr}_{2} \mathrm{O}_{7}(24 \mathrm{~h})+\mathrm{CsA}$
(8) $\mathrm{CUR}+\mathrm{K}_{2} \mathrm{Cr}_{2} \mathrm{O}_{7}(48 \mathrm{~h})$

(c)

FIGURE 10: Effect of curcumin on the mitochondrial permeability transition pore-openining from rats exposed to $\mathrm{K}_{2} \mathrm{Cr}_{2} \mathrm{O}_{7}$. (a) Mitochondrial swelling, (b) mitochondrial membrane potential dissipation, and (c) mitochondrial $\mathrm{Ca}^{2+}$ retention. Tracings are representative of three different experiments. Carbonyl cyanide m-chlorophenylhydrazone (CCCP) was added in control and curcumin groups to induce loss of membrane potential and $\mathrm{Ca}^{2+}$ release. CUR: curcumin; CsA: cyclosporine A.

pretreatment with curcumin restored oxygen consumption supporting state 3 respiration, RCI, uncoupled respiration, and ADP/O ratio, suggesting well-coupled mitochondria. Curcumin prevents mitochondrial dysfunction by maintaining redox homeostasis or by protecting the mitochondrial respiratory complex $[120,121]$.

The mitochondrial respiratory chain is one of the major sources of damaging free radicals in human organism, and unpaired electrons escaping from the respiratory complexes (mainly from complexes I and III) can lead to the formation of $\mathrm{O}_{2}{ }^{--}$by the interaction with $\mathrm{O}_{2}$ [122]. Mitochondrial complex I is a large enzyme complex of over 40 subunits embedded in the inner mitochondrial membrane and has a central role in energy production by the mitochondrial respiratory chain, providing about $40 \%$ of the proton-motive force required for the synthesis of ATP [123]. Complex I dysfunction is the most common mitochondrial defect leading to cell death and disease [124]. The present findings show that $\mathrm{K}_{2} \mathrm{Cr}_{2} \mathrm{O}_{7}$ inhibited complex I activity in a time-dependent mode. Fernandes et al. [47] showed that in rat liver mitochondria complex I was more sensitive to $\mathrm{Cr}(\mathrm{VI})$ than complex II, and the activity of cytochrome $c$ oxidase (complex IV) was not affected. Instead, curcumin pretreatment preserved the complex I activity possibly because curcumin scavenges 

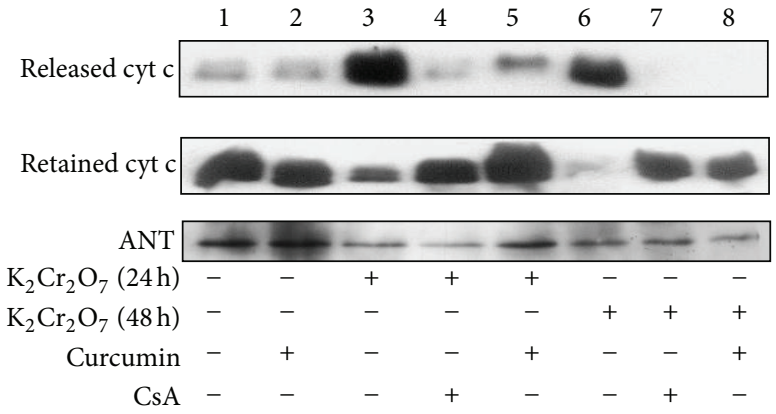

(a)

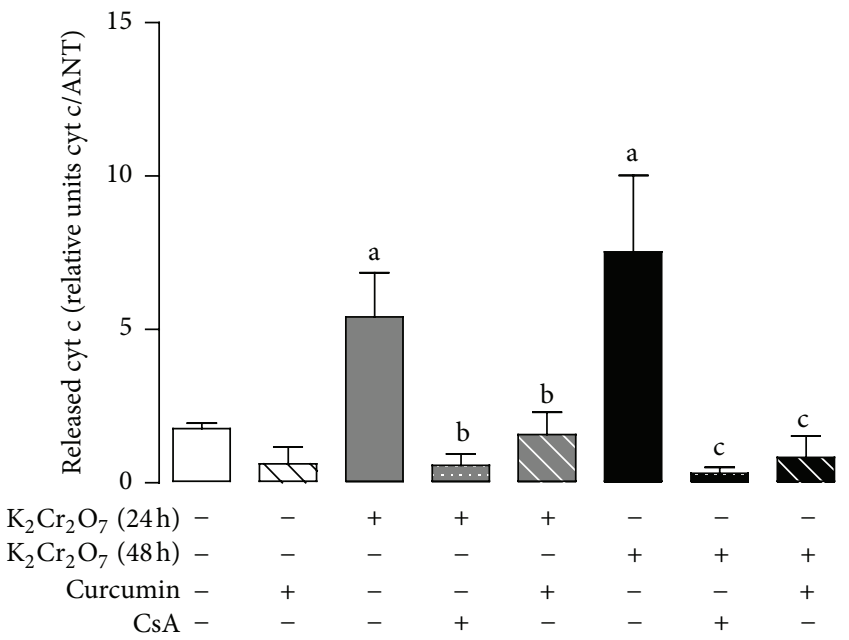

(b)

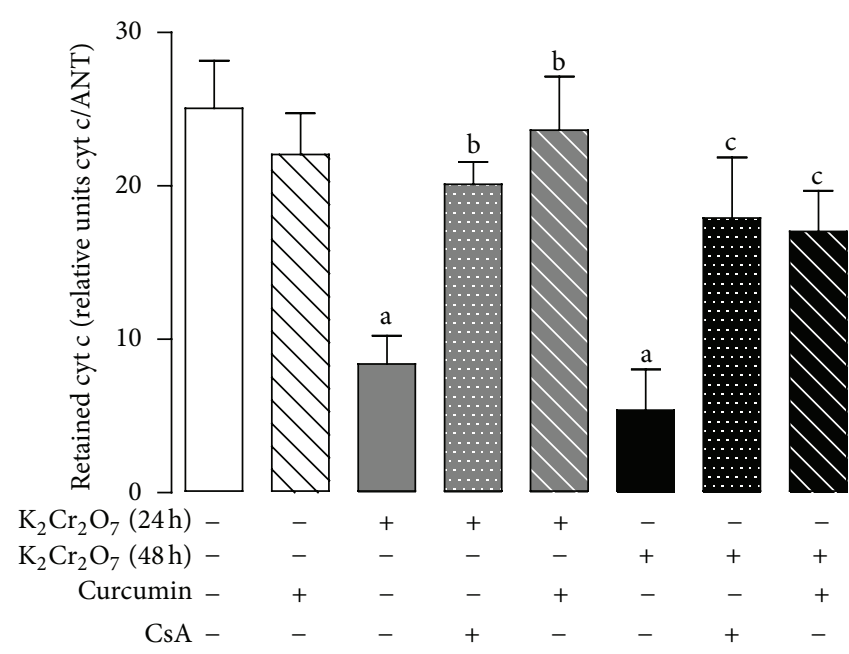

(c)

FIGURE 11: Effect of curcumin on cytochrome c (cyt c) release induced by the treatment with $\mathrm{K}_{2} \mathrm{Cr}_{2} \mathrm{O}_{7}$. Liver mitochondria were incubated for 10 min with $50 \mu \mathrm{M} \mathrm{Ca}^{2+}$, in the presence or the absence of CsA. (a) Mitochondrial cyt c released and cyt c retained by Western blot analysis, (b) cyt c released/ANT ratio, and (c) cyt c retained/ANT ratio. Values are mean $\pm \mathrm{SEM}, n=3 .{ }^{\mathrm{a}} \mathrm{P}<0.05$ versus control; ${ }^{\mathrm{b}} \mathrm{P}<0.05$ versus $\mathrm{K}_{2} \mathrm{Cr}_{2} \mathrm{O}_{7}(24 \mathrm{~h}) ;{ }^{\mathrm{c}} \mathrm{P}<0.05$ versus $\mathrm{K}_{2} \mathrm{Cr}_{2} \mathrm{O}_{7}(48 \mathrm{~h})$. ANT: adenine nucleotide translocator; CsA: cyclosporine A.

ROS or reduces ROS production in complex I. Recently, it has been reported that curcumin attenuates the inhibition of mitochondrial complex I in $\mathrm{K}_{2} \mathrm{Cr}_{2} \mathrm{O}_{7}$-induced nephrotoxicity [50], peroxynitrite-induced neurotoxicity [125], or catecholamine-induced cardiotoxicity [126].

The transfer of electrons along the respiratory chain generates an electrochemical gradient across the mitochondrial inner membrane comprising both a membrane potential and $\mathrm{H}^{+}$gradient [127]. In order to maintain those gradients, it is essential that the inner membrane of mitochondria remains impermeable or selectively permeable to metabolites and ions under normal aerobic conditions. However, in response to stress, the permeability of the mitochondrial membrane may increase, with the formation of a voltagedependent nonspecific pore in the inner membrane known as the mitochondrial PTP [128]. PTP opening causes massive swelling of mitochondria, membrane depolarization, calcium release, rupture of the outer membrane, and release of intermembrane components that induce apoptosis [129]. Thus, the results confirmed that mitochondria from livers of $\mathrm{K}_{2} \mathrm{Cr}_{2} \mathrm{O}_{7}$-treated rats presented PTP opening and cyt $\mathrm{c}$ release, as previously described by Xiao et al. [130]. in L02 hepatocyte and Pritchard et al. [131] in Chinese hamster ovary (CHO) cells. Curcumin pretreatment ameliorates the mitochondrial PTP opening from $\mathrm{K}_{2} \mathrm{Cr}_{2} \mathrm{O}_{7}$-treated rats protecting them from the noxious effects generated from $\mathrm{Cr}(\mathrm{VI})$. Besides, curcumin presents antihepatotoxic effects against ethanol-induced cytochrome $c$ translocation in cultures of isolated rat hepatocytes [132], induces protective effects against catecholamine-induced cardiotoxicity by preserving mitochondrial function [126], and prevents mitochondrial dysfunction in an aging model [133]. 
Antihepatotoxic effects of curcumin were able to inhibit the PTP opening, and this outcome was related to its antioxidant properties by suppressing both $\mathrm{O}_{2}{ }^{--}$production and lipid peroxidation [134]. In contrast, antihepatocarcinogenic effects of curcumin induces the apoptosis of tumor cells through mitochondria-dependant pathways, including the release of cyt $c$, changes in electron transport, and loss of mitochondrial transmembrane potential as has been described in human hepatocellular carcinoma J5 cells [135, 136], and HepG2 cells [137, 138], by its potent antioxidant as well as anti-inflammatory properties [139]. Thus, curcumin has a dual effect inducing PTP opening.

In summary, acute $\mathrm{K}_{2} \mathrm{Cr}_{2} \mathrm{O}_{7}$-exposure enhances the oxidative stress both by mitochondrial dysfunction as well as due to the failure in the ROS removal system that in turn causes liver injury. Curcumin pretreatment successfully attenuated hepatic damage and prevented oxidative stress and the decrease in the activity of antioxidant enzymes in both liver homogenates and isolated mitochondria. Also, curcumin ameliorated respiratory complex I activity and avoided PTP opening. All these beneficial effects of curcumin protected liver from $\mathrm{K}_{2} \mathrm{Cr}_{2} \mathrm{O}_{7}$-induced hepatotoxicity associated with mitochondrial dysfunction.

\section{Conflict of Interests}

The authors do not have any conflict of interests with the content of the paper.

\section{Acknowledgments}

This work was supported by PAPIIT (Grants nos. IN201910 and IN210713) and CONACYT (Grants nos. 167949, 177527, 129838, and 204474).

\section{References}

[1] P. Anand, C. Sundaram, S. Jhurani, A. B. Kunnumakkara, and B. B. Aggarwal, "Curcumin and cancer: an "old-age" disease with an "age-old" solution," Cancer Letters, vol. 267, no. 1, pp. 133-164, 2008.

[2] I. Chattopadhyay, K. Biswas, U. Bandyopadhyay, and R. K. Banerjee, "Turmeric and curcumin: biological actions and medicinal applications," Current Science, vol. 87, no. 1, pp. 44-53, 2004.

[3] B. Aggarwal, I. Bhatt, H. Ichikawa et al., "Curcumin-biological and medicinal properties," in Turmeric: the Genus Curcuma, Medicinal and Aromatic Plants-Industrial Profiles, pp. 297-368, CRC Press, New York, NY, USA, 2007.

[4] Y. Rivera-Espinoza and P. Muriel, "Pharmacological actions of curcumin in liver diseases or damage," Liver International, vol. 29, no. 10, pp. 1457-1466, 2009.

[5] M. Iqbal, S. D. Sharma, Y. Okazaki, M. Fujisawa, and S. Okada, "Dietary supplementation of curcumin enhances antioxidant and phase II metabolizing enzymes in ddY male mice: possible role in protection against chemical carcinogenesis and toxicity," Pharmacology and Toxicology, vol. 92, no. 1, pp. 33-38, 2003.

[6] S. Tajbakhsh, K. Mohammadi, I. Deilami et al., "Antibacterial activity of indium curcumin and indium diacetylcurcumin,"
African Journal of Biotechnology, vol. 7, no. 21, pp. 3832-3835, 2008.

[7] J. S. Jurenka, "Anti-inflammatory properties of curcumin, a major constituent of Curcuma longa: a review of preclinical and clinical research," Alternative Medicine Review, vol. 14, no. 2, pp. 141-153, 2009.

[8] B. B. Aggarwal, A. Kumar, and A. C. Bharti, "Anticancer potential of curcumin: preclinical and clinical studies," Anticancer Research, vol. 23, no. 1, pp. 363-398, 2003.

[9] E. O. Farombi, S. Shrotriya, H.-K. Na, S.-H. Kim, and Y.J. Surh, "Curcumin attenuates dimethylnitrosamine-induced liver injury in rats through Nrf2-mediated induction of heme oxygenase-1," Food and Chemical Toxicology, vol. 46, no. 4, pp. 1279-1287, 2008.

[10] A. A. Nanji, K. Jokelainen, G. L. Tipoe, A. Rahemtulla, P. Thomas, and A. J. Dannenberg, "Curcumin prevents alcoholinduced liver disease in rats by inhibiting the expression of NF$\kappa \mathrm{B}$-dependent genes," American Journal of Physiology, vol. 284, no. 2, pp. G321-G327, 2003.

[11] N. Mathuria and R. J. Verma, "Curcumin ameliorates aflatoxininduced lipid peroxidation in liver, kidney and testis of micean in vitro study," Acta Poloniae Pharmaceutica, vol. 64, no. 5, pp. 413-416, 2007.

[12] M. I. Yousef, S. A. M. Omar, M. I. El-Guendi, and L. A. Abdelmegid, "Potential protective effects of quercetin and curcumin on paracetamol-induced histological changes, oxidative stress, impaired liver and kidney functions and haematotoxicity in rat," Food and Chemical Toxicology, vol. 48, no. 11, pp. 32463261, 2010.

[13] R. A. M. Hemeida and O. M. Mohafez, "Curcumin attenuates methotraxate-induced hepatic oxidative damage in rats," Journal of the Egyptian National Cancer Institute, vol. 20, no. 2, pp. 141-148, 2008.

[14] H. S. Farghaly and M. A. Hussein, "Protective effect of curcumin against paracetamol-induced liver damage," Australian Journal of Basic and Applied Sciences, vol. 4, no. 9, pp. 4266-4274, 2010.

[15] S. Zheng, F. Yumei, and A. Chen, "De novo synthesis of glutathione is a prerequisite for curcumin to inhibit hepatic stellate cell (HSC) activation," Free Radical Biology and Medicine, vol. 43, no. 3, pp. 444-453, 2007.

[16] S. Priya and P. R. Sudhakaran, "Curcumin-induced recovery from hepatic injury involves induction of apoptosis of activated hepatic stellate cells," Indian Journal of Biochemistry and Biophysics, vol. 45, no. 5, pp. 317-325, 2008.

[17] Y. Fu, S. Zheng, J. Lin, J. Ryerse, and A. Chen, "Curcumin protects the rat liver from $\mathrm{CCl}_{4}$-caused injury and fibrogenesis by attenuating oxidative stress and suppressing inflammation," Molecular Pharmacology, vol. 73, no. 2, pp. 399-409, 2008.

[18] U. Subudhi, K. Das, B. Paital, S. Bhanja, and G. B. N. Chainy, "Alleviation of enhanced oxidative stress and oxygen consumption of l-thyroxine induced hyperthyroid rat liver mitochondria by vitamin E and curcumin," Chemico-Biological Interactions, vol. 173, no. 2, pp. 105-114, 2008.

[19] A. Pechova and L. Pavlata, "Chromium as an essential nutrient: a review," Veterinarni Medicina, vol. 52, no. 1, pp. 1-18, 2007.

[20] D. Bagchi, S. J. Stohs, B. W. Downs, M. Bagchi, and H. G. Preuss, "Cytotoxicity and oxidative mechanisms of different forms of chromium," Toxicology, vol. 180, no. 1, pp. 5-22, 2002.

[21] X. He, G. X. Lin, M. G. Chen, J. X. Zhang, and Q. Ma, "Protection against chromium (VI)-Induced oxidative stress and apoptosis by Nrf2. Recruiting Nrf2 into the nucleus and 
disrupting the nuclear Nrf2/Keap1 Association," Toxicological Sciences, vol. 98, no. 1, pp. 298-309, 2007.

[22] M. A. Armienta, O. Morton, R. Rodríguez, O. Cruz, A. Aguayo, and N. Ceniceros, "Chromium in a tannery wastewater irrigated area, León Valley, Mexico," Bulletin of Environmental Contamination and Toxicology, vol. 66, no. 2, pp. 189-195, 2001.

[23] M. Pawlikowski, E. Szalińska, M. Wardas, and J. Dominik, "Chromium originating from tanneries in river sediments: a preliminary investigation from the upper Dunajec River (Poland)," Polish Journal of Environmental Studies, vol. 15, no. 6, pp. 885-894, 2006.

[24] O. Morton-Bermea, E. Hernández-Álvarez, R. Lozano, J. Guzmán-Morales, and G. Martínez, "Spatial distribution of heavy metals in top soils around the industrial facilities of Cromatos de México, Tultitlan Mexico," Bulletin of Environmental Contamination and Toxicology, vol. 85, no. 5, pp. 520-524, 2010.

[25] J. Pedraza-Chaverrí, D. Barrera, O. N. Medina-Campos et al., "Time course study of oxidative and nitrosative stress and antioxidant enzymes in $\mathrm{K}_{2} \mathrm{Cr}_{2} \mathrm{O}_{7}$-induced nephrotoxicity," BMC Nephrology, vol. 6, article 4, 2005.

[26] A. Linos, A. Petralias, C. A. Christophi et al., "Oral ingestion of hexavalent chromium through drinking water and cancer mortality in an industrial area of Greece-an ecological study," Environmental Health, vol. 10, no. 1, article 50, 2011.

[27] A. Stift, J. Friedl, F. Längle, G. Berlakovich, R. Steininger, and F. Mühlbacher, "Successful treatment of a patient suffering from severe acute potassium dichromate poisoning with liver transplantation," Transplantation, vol. 69, no. 11, pp. 2454-2455, 2000.

[28] A. I. Rafael, A. Almeida, P. Santos et al., "A role for transforming growth factor- $\beta$ apoptotic signaling pathway in liver injury induced by ingestion of water contaminated with high levels of Cr(VI)," Toxicology and Applied Pharmacology, vol. 224, no. 2, pp. 163-173, 2007.

[29] C. Witmer, E. Faria, H. S. Park et al., "In vivo effects of chromium," Environmental Health Perspectives, vol. 102, no. 3, pp. 169-176, 1994.

[30] T.-C. Aw, "Clinical and epidemiological data on lung cancer at a chromate plant," Regulatory Toxicology and Pharmacology, vol. 26, no. 1, pp. S8-S12, 1997.

[31] C.-C. Lin, M.-L. Wu, C.-C. Yang, J. Ger, W.-J. Tsai, and J.-F. Deng, "Acute severe chromium poisoning after dermal exposure to hexavalent chromium," Journal of the Chinese Medical Association, vol. 72, no. 4, pp. 219-221, 2009.

[32] R. Shrivastava, R. K. Upreti, P. K. Seth, and U. C. Chaturvedi, "Effects of chromium on the immune system," FEMS Immunology and Medical Microbiology, vol. 34, no. 1, pp. 1-7, 2002.

[33] S. I. Nudler, F. A. Quinteros, E. A. Miler, J. P. Cabilla, S. A. Ronchetti, and B. H. Duvilanski, "Chromium VI administration induces oxidative stress in hypothalamus and anterior pituitary gland from male rats," Toxicology Letters, vol. 185, no. 3, pp. 187192, 2009.

[34] N. M. Gatto, M. A. Kelsh, D. H. Mai, M. Suh, and D. M. Proctor, "Occupational exposure to hexavalent chromium and cancers of the gastrointestinal tract: a meta-analysis," Cancer Epidemiology, vol. 34, no. 4, pp. 388-399, 2010.

[35] F. Henkler, J. Brinkmann, and A. Luch, "The role of oxidative stress in carcinogenesis induced by metals and xenobiotics," Cancers, vol. 2, no. 2, pp. 376-396, 2010.
[36] S. Ueno, T. Kashimoto, N. Susa et al., "Detection of dichromate (VI)-induced DNA strand breaks and formation of paramagnetic chromium in multiple mouse organs," Toxicology and Applied Pharmacology, vol. 170, no. 1, pp. 56-62, 2001.

[37] D. Bagchi, M. Bagchi, and S. J. Stohs, "Chromium (VI)-induced oxidative stress, apoptotic cell death and modulation of p53 tumor suppressor gene," Molecular and Cellular Biochemistry, vol. 222, no. 1-2, pp. 149-158, 2001.

[38] A. K. Patlolla, C. Barnes, C. Yedjou, V. R. Velma, and P. B. Tchounwou, "Oxidative stress, DNA damage, and antioxidant enzyme activity induced by hexavalent chromium in spraguedawley rats," Environmental Toxicology, vol. 24, no. 1, pp. 66-73, 2009.

[39] D. Bagchi, E. A. Hassoun, M. Bagchi, D. F. Muldoon, and S. J. Stohs, "Oxidative stress induced by chronic administration of sodium dichromate $[\mathrm{Cr}(\mathrm{VI})]$ to rats," Comparative Biochemistry and Physiology C, vol. 110, no. 3, pp. 281-287, 1995.

[40] K. J. Liu and X. Shi, "In vivo reduction of chromium (VI) and its related free radical generation," Molecular and Cellular Biochemistry, vol. 222, no. 1-2, pp. 41-47, 2001.

[41] S. Ueno, N. Susa, Y. Furukawa, K. Aikawa, and I. Itagaki, "Cellular injury and lipid peroxidation induced by hexavalent chromium in isolated rat hepatocytes," Nippon Juigaku Zasshi, vol. 51, no. 1, pp. 137-145, 1989.

[42] N. Soudani, I. Ben Amara, M. Sefi, T. Boudawara, and N. Zeghal, "Effects of selenium on chromium (VI)-induced hepatotoxicity in adult rats," Experimental and Toxicologic Pathology, vol. 63, no. 6, pp. 541-548, 2011.

[43] F. Woźniak, Z. Borzecki, and Z. Swies, "Histopathologic and histochemical examination of rat liver after prolonged experimental application of potassium bichromate," Annales Universitatis Mariae Curie-Sklodowska. Sectio D, vol. 46, pp. 65-68, 1991.

[44] S. Acharya, K. Mehta, S. Krishnan, and C. V. Rao, "A subtoxic interactive toxicity study of ethanol and chromium in male Wistar rats," Alcohol, vol. 23, no. 2, pp. 99-108, 2001.

[45] J. Pourahmad, A. Mihajlovic, and P. J. O’Brien, "Hepatocyte lysis induced by environmental metal toxins may involve apoptotic death signals initiated by mitochondrial injury," Advances in Experimental Medicine and Biology, vol. 500, pp. 249-252, 2001.

[46] D. Ryberg and J. Alexander, "Inhibitory action of hexavalent chromium $(\mathrm{Cr}(\mathrm{VI}))$ on the mitochondrial respiration and a possible coupling to the reduction of $\mathrm{Cr}(\mathrm{VI})$," Biochemical Pharmacology, vol. 33, no. 15, pp. 2461-2466, 1984.

[47] M. A. S. Fernandes, M. S. Santos, M. C. Alpoim, V. M. C. Madeira, and J. A. F. Vicente, "Chromium(VI) interaction with plant and animal mitochondrial bioenergetics: a comparative study," Journal of Biochemical and Molecular Toxicology, vol. 16, no. 2, pp. 53-63, 2002.

[48] D. Chorvatovicova, Z. Kovacikova, J. Sandula, and J. Navarova, "Protective effect of sulfoethylglucan against hexavalent chromium," Mutation Research, vol. 302, no. 4, pp. 207-211, 1993.

[49] N. Susa, S. Ueno, Y. Furukawa, J. Ueda, and M. Sugiyama, "Potent protective effect of melatonin on chromium(VI)induced DNA single-strand breaks, cytotoxicity, and lipid peroxidation in primary cultures of rat hepatocytes," Toxicology and Applied Pharmacology, vol. 144, no. 2, pp. 377-384, 1997.

[50] E. Molina-Jijón, E. Tapia, C. Zazueta et al., "Curcumin prevents $\mathrm{Cr}(\mathrm{VI})$-induced renal oxidant damage by a mitochondrial pathway," Free Radical Biology and Medicine, vol. 51, no. 8, pp. 1543-1557, 2011. 
[51] A. K. Chandra, A. Chatterjee, R. Ghosh, and M. Sarkar, "Effect of curcumin on chromium-induced oxidative damage in male reproductive system," Environmental Toxicology and Pharmacology, vol. 24, no. 2, pp. 160-166, 2007.

[52] E. Kim and K. J. Na, "Nephrotoxicity of sodium dichromate depending on the route of administration," Archives of Toxicology, vol. 65, no. 7, pp. 537-541, 1991.

[53] E. Coballase-Urrutia, J. Pedraza-Chaverri, N. CárdenasRodríguez et al., "Hepatoprotective effect of acetonic and methanolic extracts of Heterotheca inuloides against $\mathrm{CCl}_{4}{ }^{-}$ induced toxicity in rats," Experimental and Toxicologic Pathology, vol. 63, no. 4, pp. 363-370, 2011.

[54] O. H. Lowry, N. J. Rosebrough, A. L. Farr, and R. J. Randall, "Protein measurement with the Folin phenol reagent," The Journal of Biological Chemistry, vol. 193, no. 1, pp. 265-275, 1951.

[55] Y. I. Chirino, D. J. Sánchez-González, C. M. Martínez-Martínez, C. Cruz, and J. Pedraza-Chaverri, "Protective effects of apocynin against cisplatin-induced oxidative stress and nephrotoxicity," Toxicology, vol. 245, no. 1-2, pp. 18-23, 2008.

[56] P. D. Maldonado, D. Barrera, I. Rivero et al., "Antioxidant Sallylcysteine prevents gentamicin-induced oxidative stress and renal damage," Free Radical Biology and Medicine, vol. 35, no. 3, pp. 317-324, 2003.

[57] Y. Chirino, Y. Sánchez-Pérez, A. Osornio-Vargas et al. et al., "PM(10) impairs the antioxidant defense system and exacerbates oxidative stress driven cell death," Toxicology Letters, vol. 193, pp. 209-216, 2010.

[58] D. Barrera, P. D. Maldonado, O. N. Medina-Campos, R. Hernández-Pando, M. E. Ibarra-Rubio, and J. PedrazaChaverrí, "Protective effect of $\mathrm{SnCl}_{2}$ on $\mathrm{K}_{2} \mathrm{Cr}_{2} \mathrm{O}_{7}$-induced nephrotoxicity in rats: the indispensability of $\mathrm{HO}-1$ preinduction and lack of association with some antioxidant enzymes," Life Sciences, vol. 73, no. 23, pp. 3027-3041, 2003.

[59] J. Pedraza-Chaverrí, P. D. Maldonado, O. N. Medina-Campos et al., "Garlic ameliorates gentamicin nephrotoxicity: relation to antioxidant enzymes," Free Radical Biology and Medicine, vol. 29, no. 7, pp. 602-611, 2000.

[60] M. Orozco-Ibarra, O. Medina-Campos, D. Sánchez-González et al. et al., "Evaluation of oxidative stress in D-serine induced nephrotoxicity," Toxicology, vol. 229, pp. 123-135, 2007.

[61] J. Pedraza-Chaverrí, A. E. González-Orozco, P. D. Maldonado, D. Barrera, O. N. Medina-Campos, and R. Hernández-Pando, "Diallyl disulfide ameliorates gentamicin-induced oxidative stress and nephropathy in rats," European Journal of Pharmacology, vol. 473, no. 1, pp. 71-78, 2003.

[62] J. Pedraza-Chaverri, P. Yam-Canul, Y. I. Chirino et al., "Protective effects of garlic powder against potassium dichromateinduced oxidative stress and nephrotoxicity," Food and Chemical Toxicology, vol. 46, no. 2, pp. 619-627, 2008.

[63] E. Tapia, V. Soto, K. M. Ortiz-Vega et al., "Curcumin induces Nrf2 nuclear translocation and prevents glomerular hypertension, hyperfiltration, oxidant stress, and the decrease in antioxidant enzymes in 5/6 nephrectomized rats," Oxidative Medicine and Cellular Longevity, vol. 2012, Article ID 269039, 14 pages, 2012.

[64] F. Correa, N. García, C. Robles, E. Martínez-Abundis, and C. Zazueta, "Relationship between oxidative stress and mitochondrial function in the post-conditioned heart," Journal of Bioenergetics and Biomembranes, vol. 40, no. 6, pp. 599-606, 2008.
[65] A. Zúñiga-Toalá, E. Tapia, C. Zazueta et al. et al., "Nordihydroguaiaretic acid pretreatment prevents ischemia and reperfusion induced renal injury, oxidant stress and mitochondrial alterations," Journal of Medicinal Plants Research, vol. 6, pp. 2938-2947, 2012.

[66] F. Correa, V. Soto, and C. Zazueta, "Mitochondrial permeability transition relevance for apoptotic triggering in the postischemic heart," International Journal of Biochemistry and Cell Biology, vol. 39, no. 4, pp. 787-798, 2007.

[67] N. García, C. Zazueta, R. Carrillo, F. Correa, and E. Chávez, "Copper sensitizes the mitochondrial permeability transition to carboxytractyloside and oleate," Molecular and Cellular Biochemistry, vol. 209, no. 1-2, pp. 119-123, 2000.

[68] C. Zazueta, N. García, E. Martínez-Abundis, N. Pavón, L. Hernández-Esquivel, and E. Chávez, "Reduced capacity of $\mathrm{Ca}^{2+}$ retention in liver as compared to kidney mitochondria. ADP requirement," Journal of Bioenergetics and Biomembranes, vol. 42, no. 5, pp. 381-386, 2010.

[69] C. Zazueta, M. Franco, F. Correa et al., "Hypothyroidism provides resistance to kidney mitochondria against the injury induced by renal ischemia-reperfusion," Life Sciences, vol. 80, no. 14, pp. 1252-1258, 2007.

[70] S. Kumar and S. Roy, "Effect of chromium on certain aspects of cellular toxicity," Iranian Journal of Toxicology, vol. 2, pp. 260267, 2009.

[71] D. E. Amacher, "Serum transaminase elevations as indicators of hepatic injury following the administration of drugs," Regulatory Toxicology and Pharmacology, vol. 27, no. 2, pp. 119-130, 1998.

[72] Z. Hassan, M. Elobeid, P. Virk et al., "Bisphenol A induces hepatotoxicity through oxidative stress in rat model," Oxidative Medicine and Cellular Longevity, vol. 2012, Article ID 194829, 6 pages, 2012.

[73] S. Kalayarasan, N. Sriram, A. Sureshkumar, and G. Sudhandiran, "Chromium (VI)-induced oxidative stress and apoptosis is reduced by garlic and its derivative $\mathrm{S}$-allylcysteine through the activation of Nrf2 in the hepatocytes of Wistar rats," Journal of Applied Toxicology, vol. 28, no. 7, pp. 908-919, 2008.

[74] A. C. P. Reddy and B. R. Lokesh, "Effect of curcumin and eugenol on iron-induced hepatic toxicity in rats," Toxicology, vol. 107, no. 1, pp. 39-45, 1996.

[75] M.-E. Wang, Y.-C. Chen, I.-S. Chen, S.-C. Hsieh, S.-S. Chen, and C.-H. Chiu, "Curcumin protects against thioacetamideinduced hepatic fibrosis by attenuating the inflammatory response and inducing apoptosis of damaged hepatocytes," Journal of Nutritional Biochemistry, 2012.

[76] D. Han, N. Hanawa, B. Saberi, and N. Kaplowitz, "Mechanisms of liver injury. III. Role of glutathione redox status in liver injury," American Journal of Physiology, vol. 291, no. 1, pp. G1G7, 2006.

[77] E. Kheradpezhouh, M.-R. Panjehshahin, R. Miri et al., "Curcumin protects rats against acetaminophen-induced hepatorenal damages and shows synergistic activity with $\mathrm{N}$-acetyl cysteine," European Journal of Pharmacology, vol. 628, no. 1-3, pp. 274-281, 2010.

[78] P. Sankar, A. G. Telang, and A. Manimaran, "Protective effect of curcumin on cypermethrin-induced oxidative stress in Wistar rats," Experimental and Toxicologic Pathology, vol. 64, no. 5, pp. 487-493, 2012.

[79] R. Von Burg and D. Liu, "Chromium and hexavalent chromium," Journal of Applied Toxicology, vol. 13, no. 3, pp. 225-230, 1993. 
[80] M. Costa, "Toxicity and carcinogenicity of $\mathrm{Cr}(\mathrm{VI})$ in animal models and humans," Critical Reviews in Toxicology, vol. 27, no. 5, pp. 431-442, 1997.

[81] S. S. Anand, "Protective effect of vitamin B6 in chromiuminduced oxidative stress in liver," Journal of Applied Toxicology, vol. 25, no. 5, pp. 440-443, 2005.

[82] M. V. Rao, S. S. Parekh, and S. L. Chawla, "Vitamin-E supplementation ameliorates chromium-and/or nickel induced oxidative stress in vivo," Journal of Health Science, vol. 52, no. 2, pp. 142-147, 2006.

[83] D. Chorvatovicova, E. Ginter, A. Kosinova, and Z. Zloch, "Effect of vitamins $\mathrm{C}$ and $\mathrm{E}$ on toxicity and mutagenicity of hexavalent chromium in rat and guinea pig," Mutation Research, vol. 262, no. 1, pp. 41-46, 1991.

[84] N. Susa, S. Ueno, and Y. Furukawa, "Protective effects of thiol compounds on chromate-induced toxicity in vitro and in vivo," Environmental Health Perspectives, vol. 102, no. 3, pp. 247-250, 1994.

[85] I. I. Boşgelmez, T. Söylemezoǧlu, and G. Güvendik, “The protective and antidotal effects of taurine on hexavalent chromiuminduced oxidative stress in mice liver tissue," Biological Trace Element Research, vol. 125, no. 1, pp. 46-58, 2008.

[86] Q.-Y. Wei, W.-F. Chen, B. Zhou, L. Yang, and Z.-L. Liu, "Inhibition of lipid peroxidation and protein oxidation in rat liver mitochondria by curcumin and its analogues," Biochimica et Biophysica Acta, vol. 1760, no. 1, pp. 70-77, 2006.

[87] H. Alp, I. Aytekin, N. Hatipoglu, A. Alp, and M. Ogun, "Effects of sulforophane and curcumin on oxidative stress created by acute malathion toxicity in rats," European Review For Medical and Pharmacological Sciences, vol. 16, pp. 144-148, 2012.

[88] M. Tokaç, G. Taner, S. Aydın et al. et al., "Protective effects of curcumin against oxidative stress parameters and DNA damage in the livers and kidneys of rats with biliary obstruction," Food and Chemical Toxicology, vol. 6915, pp. 53-57, 2013.

[89] A. A. M. Adly, "Oxidative stress and disease: an updated review," Research Journal of Immunology, vol. 3, no. 2, pp. 129-145, 2010.

[90] I. Dalle-Donne, R. Rossi, D. Giustarini, A. Milzani, and R. Colombo, "Protein carbonyl groups as biomarkers of oxidative stress," Clinica Chimica Acta, vol. 329, no. 1-2, pp. 23-38, 2003.

[91] T. Ak and I. Gülçin, "Antioxidant and radical scavenging properties of curcumin," Chemico-Biological Interactions, vol. 174, no. 1, pp. 27-37, 2008.

[92] A. T. Dinkova-Kostova and P. Talalay, "Direct and indirect antioxidant properties of inducers of cytoprotective proteins," Molecular Nutrition and Food Research, vol. 52, no. 1, pp. S128S138, 2008.

[93] V. I. Lushchak, "Glutathione homeostasis and functions: potential targets for medical interventions," Journal of Amino Acids, vol. 2012, Article ID 736837, 26 pages, 2012.

[94] L. L. P. Gutierrez, N. C. Mazzotti, A. S. R. Araújo et al., "Peripheral markers of oxidative stress in chronic mercuric chloride intoxication," Brazilian Journal of Medical and Biological Research, vol. 39, no. 6, pp. 767-772, 2006.

[95] S. Whillier, P. Kuchel, and J. Raftos, "Oxidative stress in type II diabetes mellitus and the role of the endogenous antioxidant glutathione," in Role of the Adipocyte in Development of Type 2 Diabetes, C. Croniger, Ed., pp. 129-252, InTech Europe, Croatia, 2011.

[96] D. S. El-Agamy, "Comparative effects of curcumin and resveratrol on aflatoxin B 1-induced liver injury in rats," Archives of Toxicology, vol. 84, no. 5, pp. 389-396, 2010.
[97] J. Matés, C. Pérez-Gómez, and I. N. de Castro, "Antioxidant enzymes and human diseases," Clinical Biochemistry, vol. 32, pp. 595-603, 1999.

[98] A. C. Elia, A. J. M. Dörr, C. Mastrangelo, M. Prearo, and M. C. Abete, "Glutathione and antioxidant enzymes in the hepatopancreas of crayfish Procambarus clarkii (Girard, 1852) of Lake Trasimeno (Italy)," Bulletin Francais de la Peche et de la Protection des Milieux Aquatiques, no. 380-381, pp. 1351-1361, 2006.

[99] F. M. El-Demerdash, M. I. Yousef, and F. M. E. Radwan, "Ameliorating effect of curcumin on sodium arsenite-induced oxidative damage and lipid peroxidation in different rat organs," Food and Chemical Toxicology, vol. 47, no. 1, pp. 249-254, 2009.

[100] X. Guangwei, L. Rongzhu, X. Wenrong et al., "Curcumin pretreatment protects against acute acrylonitrile-induced oxidative damage in rats," Toxicology, vol. 267, no. 1-3, pp. 140-146, 2010.

[101] S. Al-Jassabi, M. Azirun, and A. Saad, "Biochemical studies on the role of curcumin in the potection of liver and kidney damage by anti-malaria drug, chloroquine," American-Eurasian Journal of Toxicological Sciences, vol. 3, pp. 17-22, 2011.

[102] V. Mathews, P. Binu, M. Sauganth-Paul, M. Abhilash, A. Manju, and R. Nair, "Hepatoprotective efficacy of curcumin against arsenic trioxide toxicity," Asian Pacific Journal of Tropical Biomedicine, vol. 2, pp. S706-S711, 2012.

[103] Y. Wei, R. S. Rector, J. P. Thyfault, and J. A. Ibdah, "Nonalcoholic fatty liver disease and mitochondrial dysfunction," World Journal of Gastroenterology, vol. 14, no. 2, pp. 193-199, 2008.

[104] M. Königsberg, N. E. López-Díazguerrero, L. Bucio, and M. C. Gutiérrez-Ruiz, "Uncoupling effect of mercuric chloride on mitochondria isolated from an hepatic cell line," Journal of Applied Toxicology, vol. 21, no. 4, pp. 323-329, 2001.

[105] G. T. Vatassery, E. G. DeMaster, J. C. K. Lai, W. E. Smith, and H. T. Quach, "Iron uncouples oxidative phosphorylation in brain mitochondria isolated from vitamin E-deficient rats," Biochimica et Biophysica Acta, vol. 1688, no. 3, pp. 265-273, 2004.

[106] G. L. P. Andreu, N. M. Inada, A. E. Vercesi, and C. Curti, "Uncoupling and oxidative stress in liver mitochondria isolated from rats with acute iron overload," Archives of Toxicology, vol. 83, no. 1, pp. 47-53, 2009.

[107] D. N. Roy, S. Mandal, G. Sen, and T. Biswas, "Superoxide anion mediated mitochondrial dysfunction leads to hepatocyte apoptosis preferentially in the periportal region during copper toxicity in rats," Chemico-Biological Interactions, vol. 182, no. 23, pp. 136-147, 2009.

[108] A. Navarro and A. Boveris, "Rat brain and liver mitochondria develop oxidative stress and lose enzymatic activities on aging," American Journal of Physiology, vol. 287, no. 5, pp. R1244-R1249, 2004.

[109] M. Jurczuk, J. Moniuszko-Jakoniuk, and J. Rogalska, "Evaluation of oxidative stress in hepatic mitochondria of rats exposed to cadmium and ethanol," Polish Journal of Environmental Studies, vol. 15, no. 6, pp. 853-860, 2006.

[110] R. Jasso-Chávez, A. Pacheco-Rosales, E. Lira-Silva, J. C. Gallardo-Pérez, N. García, and R. Moreno-Sánchez, "Toxic effects of $\mathrm{Cr}(\mathrm{VI})$ and $\mathrm{Cr}(\mathrm{III})$ on energy metabolism of heterotrophic Euglena gracilis," Aquatic Toxicology, vol. 100, no. 4, pp. 329-338, 2010.

[111] K. Rembacz, E. Sawicka, and A. Długosz, "Role of estradiol in chromium-induced oxidative stress," Acta Poloniae Pharmaceutica, vol. 69, pp. 1372-1379, 2012. 
[112] K. I. Priyadarsini, D. K. Maity, G. H. Naik et al., "Role of phenolic $\mathrm{O}-\mathrm{H}$ and methylene hydrogen on the free radical reactions and antioxidant activity of curcumin," Free Radical Biology and Medicine, vol. 35, no. 5, pp. 475-484, 2003.

[113] Y.-G. Zhu, X.-C. Chen, Z.-Z. Chen et al., "Curcumin protects mitochondria from oxidative damage and attenuates apoptosis in cortical neurons," Acta Pharmacologica Sinica, vol. 25, no. 12, pp. 1606-1612, 2004.

[114] A. González-Salazar, E. Molina-Jijón, F. Correa et al., "Curcumin protects from cardiac reperfusion damage by attenuation of oxidant stress and mitochondrial dysfunction," Cardiovascular Toxicology, vol. 11, no. 4, pp. 357-364, 2011.

[115] H. He, G. Wang, Y. Gao, W. Ling, Z. Yu, and T. Jin, "Curcumin attenuates Nrf2 signaling defect, oxidative stress in muscle and glucose intolerance in high fat diet-fed mice," World Journal of Diabetes, vol. 3, pp. 94-104, 2012.

[116] M. Waseem, P. Kaushik, and S. Parvez, "Mitochondriamediated mitigatory role of curcumin in cisplatin-induced nephrotoxicity," Cell Biochemistry and Function, 2013.

[117] V. Calabrese, R. Lodi, C. Tonon et al., "Oxidative stress, mitochondrial dysfunction and cellular stress response in Friedreich's ataxia," Journal of the Neurological Sciences, vol. 233, no. 1-2, pp. 145-162, 2005.

[118] M. T. Lin and M. F. Beal, "Mitochondrial dysfunction and oxidative stress in neurodegenerative diseases," Nature, vol. 443, no. 7113, pp. 787-795, 2006.

[119] C. P. M. S. Oliveira, A. M. M. Coelho, H. V. Barbeiro et al., "Liver mitochondrial dysfunction and oxidative stess in the pathogenesis of experimental nonalcoholic fatty liver disease," Brazilian Journal of Medical and Biological Research, vol. 39, no. 2, pp. 189-194, 2006.

[120] H. Raza, A. John, E. M. Brown, S. Benedict, and A. Kambal, "Alterations in mitochondrial respiratory functions, redox metabolism and apoptosis by oxidant 4-hydroxynonenal and antioxidants curcumin and melatonin in PC12 cells," Toxicology and Applied Pharmacology, vol. 226, no. 2, pp. 161-168, 2008.

[121] N. Sivalingam, J. Basivireddy, K. A. Balasubramanian, and M. Jacob, "Curcumin attenuates indomethacin-induced oxidative stress and mitochondrial dysfunction," Archives of Toxicology, vol. 82, no. 7, pp. 471-481, 2008.

[122] K. Sas, H. Robotka, J. Toldi, and L. Vécsei, "Mitochondria, metabolic disturbances, oxidative stress and the kynurenine system, with focus on neurodegenerative disorders," Journal of the Neurological Sciences, vol. 257, no. 1-2, pp. 221-239, 2007.

[123] R. G. Efremov, R. Baradaran, and L. A. Sazanov, "The architecture of respiratory complex I," Nature, vol. 465, no. 7297, pp. 441445,2010

[124] D. Gonzalez-Halphen, A. Ghelli, L. Iommarini, V. Carelli, and M. D. Esposti, "Mitochondrial complex I and cell death: a semiautomatic shotgun model," Cell Death and Disease, vol. 2, no. 10, article e222, 2011.

[125] R. B. Mythri, G. Harish, S. K. Dubey, K. Misra, and M. M. Srinivas Bharath, "Glutamoyl diester of the dietary polyphenol curcumin offers improved protection against peroxynitritemediated nitrosative stress and damage of brain mitochondria in vitro: implications for Parkinson's disease," Molecular and Cellular Biochemistry, vol. 347, no. 1-2, pp. 135-143, 2011.

[126] M. Izem-Meziane, B. Djerdjouri, S. Rimbaud et al., "Catecholamine-induced cardiac mitochondrial dysfunction and MPTP opening: protective effect of curcumin," American Journal of Physiology, vol. 302, no. 3, pp. H665-H674, 2012.
[127] G. Feldmann, D. Haouzi, A. Moreau et al., "Opening of the mitochondrial permeability transition pore causes matrix expansion and outer membrane rupture in Fas-mediated hepatic apoptosis in mice," Hepatology, vol. 31, no. 3, pp. 674-683, 2000.

[128] S. Javadov and M. Karmazyn, "Mitochondrial permeability transition pore opening as an endpoint to initiate cell death and as a putative target for cardioprotection," Cellular Physiology and Biochemistry, vol. 20, no. 1-4, pp. 1-22, 2007.

[129] A. P. Halestrap, G. P. McStay, and S. J. Clarke, “The permeability transition pore complex: another view," Biochimie, vol. 84, no. 2-3, pp. 153-166, 2002.

[130] J.-W. Xiao, C.-G. Zhong, and B. Li, "Study of L-02 hepatocyte apoptosis induced by hexavalent chromium associated with mitochondria function damage," Wei Sheng Yan Jiu, vol. 35, no. 4, pp. 416-418, 2006.

[131] D. E. Pritchard, J. Singh, D. L. Carlisle, and S. R. Patierno, "Cyclosporin A inhibits chromium(VI)-induced apoptosis and mitochondrial cytochrome $\mathrm{c}$ release and restores clonogenic survival in CHO cells," Carcinogenesis, vol. 21, no. 11, pp. 20272033, 2000.

[132] A. I. Ghoneim, "Effects of curcumin on ethanol-induced hepatocyte necrosis and apoptosis: implication of lipid peroxidation and cytochrome c," Naunyn-Schmiedeberg's Archives of Pharmacology, vol. 379, no. 1, pp. 47-60, 2009.

[133] G. Eckert, C. Schiborr, S. Hagl et al., "Curcumin prevents mitochondrial dysfunction in the brain of the senescenceaccelerated mouse-prone 8," Neurochemistry International, vol. 62, pp. 595-602, 2013.

[134] H. Ligeret, S. Barthelemy, R. Zini, J.-P. Tillement, S. Labidalle, and D. Morin, "Effects of curcumin and curcumin derivatives on mitochondrial permeability transition pore," Free Radical Biology and Medicine, vol. 36, no. 7, pp. 919-929, 2004.

[135] C.-Y. Cheng, Y.-H. Lin, and C.-C. Su, "Curcumin inhibits the proliferation of human hepatocellular carcinoma J5 cells by inducing endoplasmic reticulum stress and mitochondrial dysfunction," International Journal of Molecular Medicine, vol. 26, no. 5, pp. 673-678, 2010.

[136] W. Wang, I. Chiang, K. Ding et al., "Curcumin-induced apoptosis in human hepatocellular carcinoma J5 cells: critical role of $\mathrm{Ca}^{+2}$-dependent pathway," Evidence-Based Complementary and Alternative Medicine, vol. 2012, Article ID 512907, 7 pages, 2012.

[137] J. Cao, Y. Liu, L. Jia et al., "Curcumin induces apoptosis through mitochondrial hyperpolarization and mtDNA damage in human hepatoma G2 cells," Free Radical Biology and Medicine, vol. 43, no. 6, pp. 968-975, 2007.

[138] M. Wang, Y. Ruan, Q. Chen, S. Li, Q. Wang, and J. Cai, "Curcumin induced HepG2 cell apoptosis-associated mitochondrial membrane potential and intracellular free $\mathrm{Ca}^{2+}$ concentration," European Journal of Pharmacology, vol. 650, no. 1, pp. 41-47, 2011.

[139] A. S. Darvesha, B. B. Aggarwal, and A. Bishayee, "Curcumin and liver cancer: a review," Current Pharmaceutical Biotechnology, vol. 13, no. 1, pp. 218-228, 2012. 


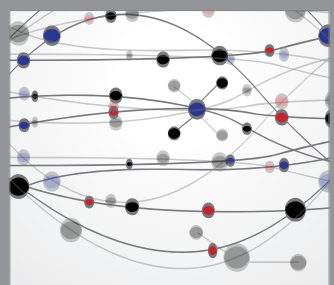

The Scientific World Journal
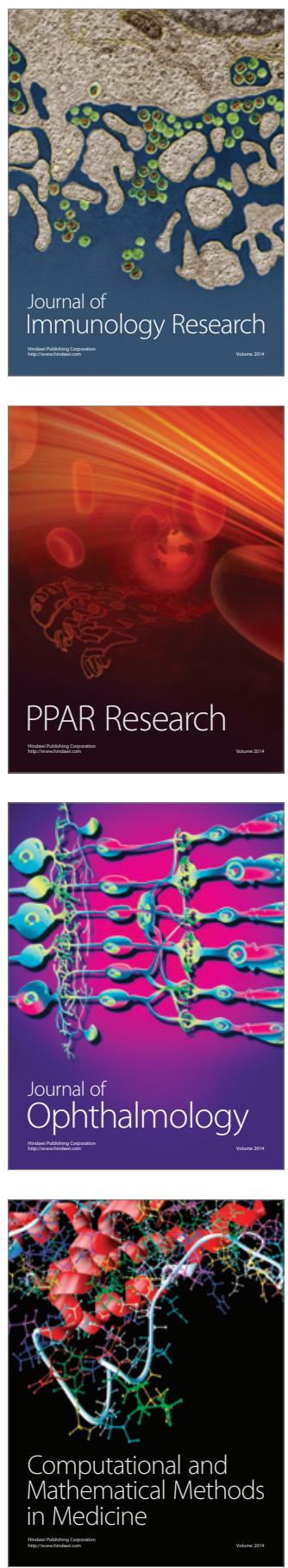

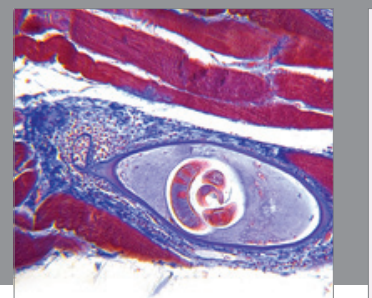

Gastroenterology

Research and Practice
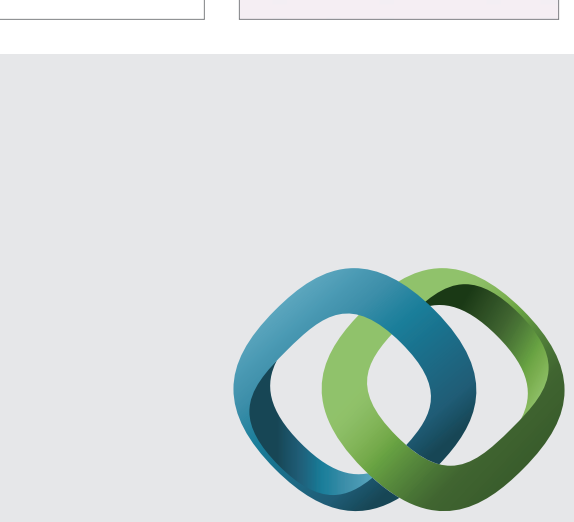

\section{Hindawi}

Submit your manuscripts at

http://www.hindawi.com
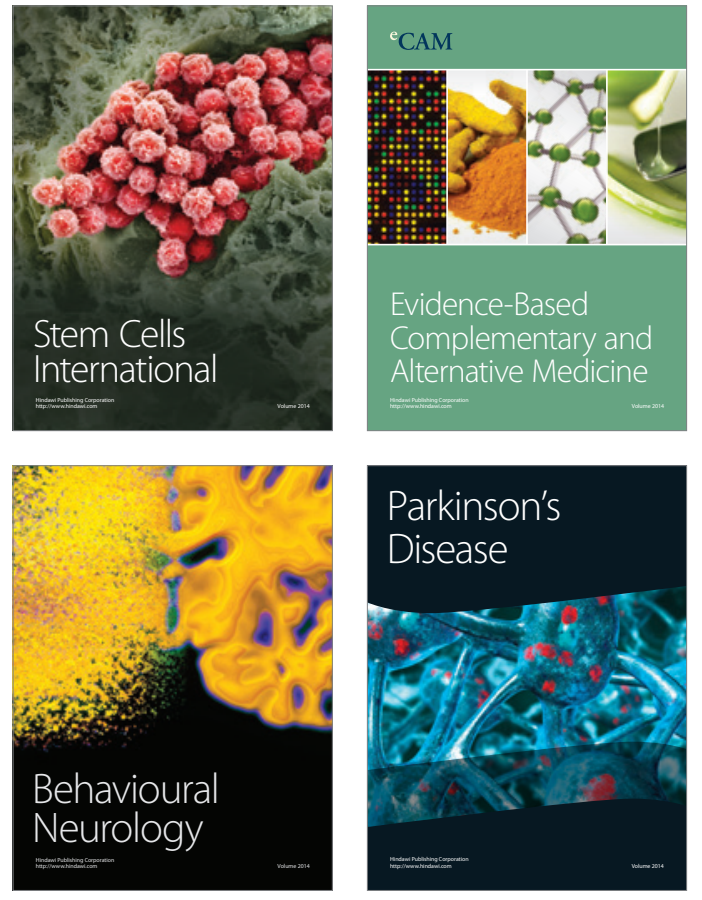
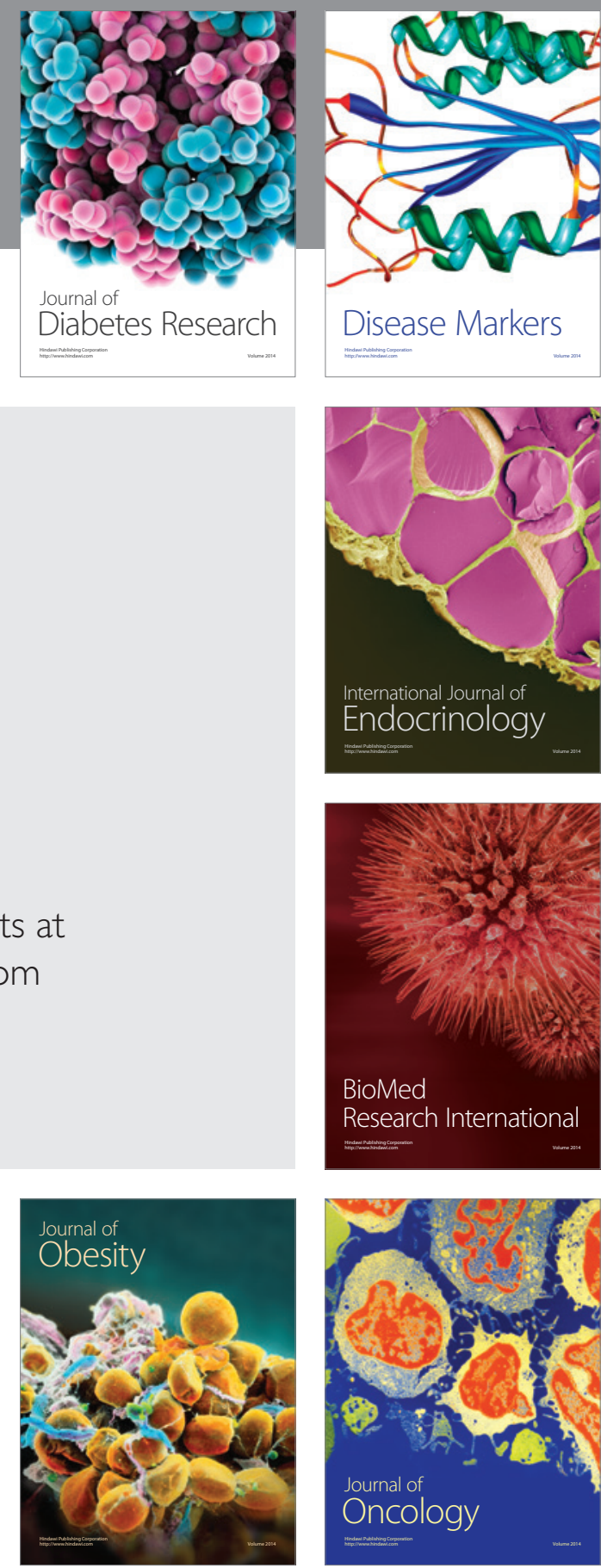

Disease Markers
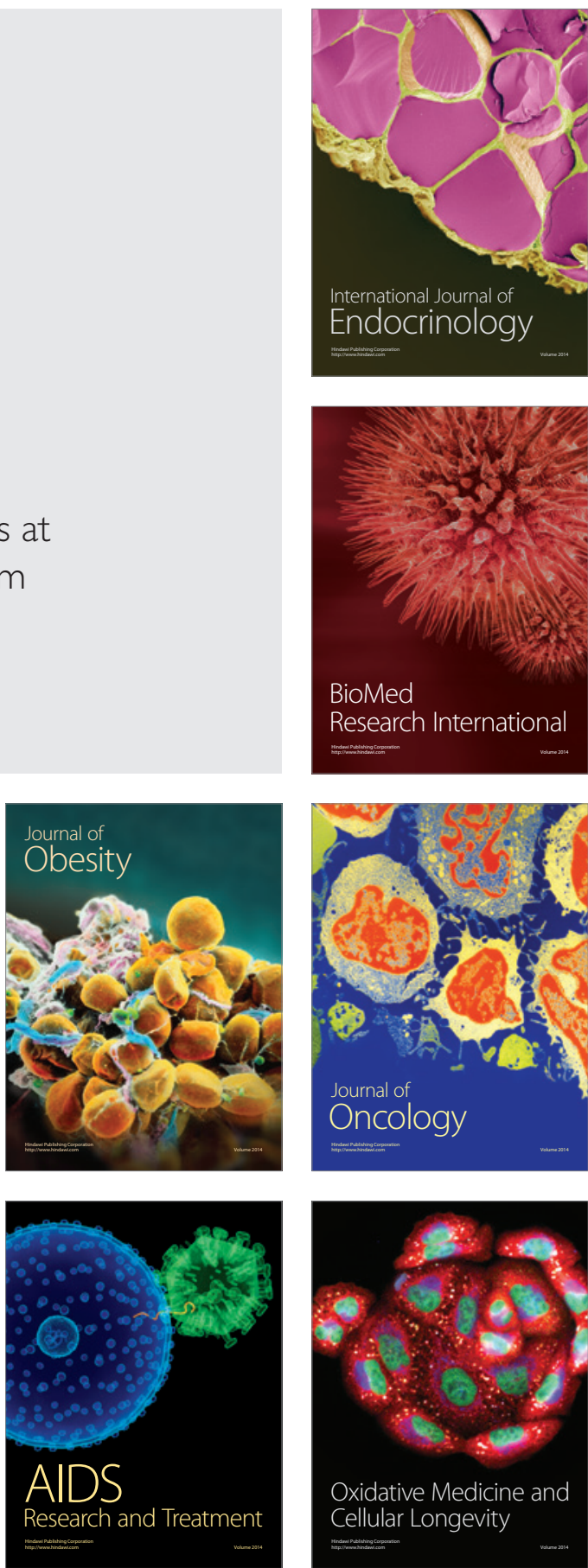